\title{
Fuel-Rich Methane Oxidation in a High-Pressure Flow Reactor studied by Optical-Fiber Laser-Induced Fluorescence, Multi-Species Sampling Profile Measurements and Detailed Kinetic Simulations
}

\author{
Heiner Schwarz ${ }^{\mathrm{a}}$, Michael Geske ${ }^{\mathrm{b}}$, C. Franklin Goldsmith ${ }^{\mathrm{c}}$, Robert Schlögl ${ }^{\mathrm{a}}$, Raimund Horn ${ }^{\mathrm{d}, *}$ \\ ${ }^{a}$ Department of Inorganic Chemistry, Fritz Haber Institute of the Max Planck Society, Faradayweg 4-6, 14195 Berlin, Germany \\ ${ }^{b}$ BasCat UniCat-BASF Joint Lab, Technische Universität Berlin, Marchstraße 6, 10587 Berlin, Germany \\ ${ }^{c}$ Chemical and Biochemical Engineering, Brown University, Providence, Rhode Island 02912, United States of America \\ ${ }^{d}$ Institute of Chemical Reaction Engineering, Hamburg University of Technology, Eißendorfer Straße 38, 21073 Hamburg, Germany
}

\begin{abstract}
A versatile flow-reactor design is presented that permits multi-species profile measurements under industrially relevant temperatures and pressures. The reactor combines a capillary sampling technique with a novel fiber-optic Laser-Induced Fluorescence (LIF) method. The gas sampling provides quantitative analysis of stable species by means of gas chromatography (i.e. $\mathrm{CH}_{4}, \mathrm{O}_{2}, \mathrm{CO}, \mathrm{CO}_{2}$, $\mathrm{H}_{2} \mathrm{O}, \mathrm{H}_{2}, \mathrm{C}_{2} \mathrm{H}_{6}, \mathrm{C}_{2} \mathrm{H}_{4}$ ), and the fiber-optic probe enables in situ detection of transient LIF-active species, demonstrated here for $\mathrm{CH}_{2} \mathrm{O}$. A thorough analysis of the LIF correction terms for the temperature-dependent Boltzmann fraction and collisional quenching are presented. The laminar flow reactor is modeled by solving the two-dimensional Navier-Stokes equations in conjunction with a detailed kinetic mechanism. Experimental and simulated profiles are compared. The experimental profiles provide much needed data for the continued validation of the kinetic mechanism with respect to $C_{1}$ and $C_{2}$ chemistry; additionally, the results provide mechanistic insight into the reaction network of fuel-rich gas-phase methane oxidation, thus allowing optimization of the industrial process.
\end{abstract}

Keywords: Oxidative Coupling of Methane, OCM, High-Pressure Profile Reactor, Multi-Species Sampling, Fiber-Optic Laser-Indcued Fluorescence, LIF, Formaldehyde, CH2O, Chemical Kinetics, Elementary Kinetics, Reactor Modeling Computational Fluid Dynamics, CFD

\section{Introduction}

Owing to the predicted depletion of petroleum reserves, the transformation of natural gas (i.e. methane) into value-added chemical products is of growing interest for the chemical industry. Conventional approaches rely on indirect conversion via synthesis gas production (from steam reforming, $\mathrm{CO}_{2}$ reforming or partial oxidation), followed by a gas-to-liquid process, but these multi-step processes are particularly capital intensive. Therefore, the direct conversion of methane to ethylene, methanol or formaldehyde is economically more favorable $[1,2]$.

Oxidative Coupling of Methane (OCM) could be a desirable direct conversion route in which methane is transformed into ethylene under fuel-rich conditions $\left(\mathrm{CH}_{4} / \mathrm{O}_{2}=2-8\right.$, or an equivalence ratio $\phi=4-16$ ) at temperatures around $1000 \mathrm{~K}$ and pressures up to $30 \mathrm{bar}$. It has been suggested in the literature that the OCM reaction proceeds via a homogeneous/heterogeneous coupled mechanism [3,4]. According to this model, methane is first activated on the catalyst, and the resulting methyl radical desorbs. Two gas-phase methyl radicals combine to form ethane, which is subsequently dehydrogenated to ethylene. In fact, OCM can occur even without a catalysts, albeit with very

${ }^{*}$ Corresponding author low selectivity $[5,6,7,8]$. Although the exact role of oxygen in the homogeneous/heterogeneous mechanism is unclear, it is known that small concentrations of oxygen are necessary for OCM. If the concentration of oxygen is too high, however, the $\mathrm{C}_{2}$ products will be oxidized, thereby decreasing the yield. Computational engineering will play a key role in the optimization of the reactor design, catalyst choice, and operating conditions. An essential component of this approach includes detailed models that describe the coupling between fluid mechanics and the kinetics of elementary surface and gas phase reactions. The predictive utility of these models depends upon the accuracy of the underlying rate coefficients for the elementary reactions. These kinetic ${ }^{1}$ mechanisms are often tested against experimental data taken under low-pressure and/or highly dilute conditions. A more desirable approach would be to validate the mechanisms against data taken under industrially relevant conditions, since it requires less extrapolation, but this approach can work only if the flow field and chemistry can be modeled simultaneously in a rigorous yet computationally efficient manner. This manuscript presents an experimental apparatus designed precisely for this purpose and the accompanying kinetic

\footnotetext{
${ }^{1}$ Mechanisms of elementary rate constants are commonly referred to as "microkinetic" in the catalysis community, whereas the preferred term in gas-phase chemistry is "detailed kinetics" or "elementary kinetics".
} 
simulations.

Gas-phase Oxidative Coupling of Methane was studied in a novel, versatile flow reactor designed for spatially resolved kinetic profile measurements under homogeneous (and/or catalytic) conditions, with temperatures up to $1300 \mathrm{~K}$ and pressures up to 45 bar [9]. The reactor features a sampling capillary through which a small fraction of the reacting gas mixture is transferred to quantitative gas analytics, e.g. a mass spectrometer (MS) or a gas chromatograph (GC). Complementarily, a recently developed fiber-optic Laser-Induced Fluorescence (LIF) method [10] was applied for in situ detection of $\mathrm{CH}_{2} \mathrm{O}$, which is an important intermediate in the oxidation process. It is worth emphasizing that the reactor does not require optical viewports; optical access is provided only via the novel fiber-optic LIF probe. This technique is of particular interest for applications where optical access is limited (e.g. high-pressure reactors or internal combustion engines).

Section 2.1 describes the experimental design of the profile reactor, in particular the sampling process as well as the temperature and species analysis. Section 2.2 outlines the optical setup of the fiber-endoscopic LIF method, and Section 2.3 details the corrections necessary to derive relative concentration measurement from the LIF data, including collisional quenching and the temperature-dependance of the exited state populations. Section 3 describes the reactor modeling using Computational Fluid Dynamics (CFD) and the required reduction procedure of the kinetic mechanism. In Section 4 the results of experiment and simulation are presented and discussed, followed by a kinetic description of the elementary reaction steps.

\section{Experimental Methods}

\subsection{Profile Reactor Measurements}

A detailed description of the reactor design is given in [9]; the essential features of the profile reactor are schematically summarized in Figure 1. The flow reactor consists of a cylindrical fused-silica tube of $18 \mathrm{~mm}$ inner diameter and $10 \mathrm{~mm}$ thick walls. It is enclosed by an electrical furnace (not shown in the drawing), the temperature of which is monitored using a thermocouple. The gas flow is regulated by calibrated mass-flow controllers for $\mathrm{CH}_{4}, \mathrm{O}_{2}$, and $\mathrm{Ar} / \mathrm{He}$ mixture (8 vol-\% He in Ar, serving as internal standard and carrier gas for the analytics).

Sampling of the reacting gas mixture is accomplished by means of a fused-silica capillary (outer diameter $652 \mu \mathrm{m}$ ). The capillary is translated along the reactor axis allowing continuous sampling of the reacting gas mixture and thus a determination of the chemical composition as a function of position. A K-type thermocouple can be inserted in the capillary void, additionally providing information about the axial temperature profile. An $\alpha$-alumina foam ( 80 pores per linear inch) provides mechanical stability for the sampling capillary and allows efficient preheating of the gas stream prior to entering the free gasphase region. The sampling rates $(\sim 10 \mathrm{ml} / \mathrm{min})$ are adjusted such that they are considerably smaller than the total flow rate, so that (i) the flow remains largely unaffected from the sampling and (ii) the sampling volume remains small. It was verified experimentally and numerically (i.e. by CFD simulations of the sampling process) that the spatial resolution is on the order of several hundreds of microns so that profile gradients are not limited by the spatial resolution of the technique.

When probing a reacting gas mixture one has to ensure rapid quenching of the chemical reaction in order to achieve an unbiased measurement at the probing position. This may be assured if either (i) the sampling time is short compared to changes in chemical composition (i.e. rapid extraction), or if (ii) heat or radical removal by collisional wall-quenching inhibits reaction progress. In our experiments, the reaction timescale is on the order of $0.1 \mathrm{~s}$ while sampling occurs on a slightly shorter timescale, so that the first condition may not suffice to justify unbiased sampling. However, quenching distances of $\sim 1 \mathrm{~mm}$ between silica walls, even when maintained at $1000 \mathrm{~K}$, are generally sufficient to suppress a reaction [11]. Since in the present experiment the wall distance inside the capillary is much smaller $(\sim 100 \mu \mathrm{m})$ it can be assumed that thanks to wallquenching (i.e. by radical recombination) an unbiased composition of the reaction gas is analyzed.

The sampled gas is transfered to a mass spectrometer for online monitoring of the reaction. Additionally, quantitative detection of the stable gas-phase species is attained by a micro gas-chromatograph (Varian, model CP-4900). The micro-GC consists of two columns: a Molsieve 5 A column for the permanent gases $\mathrm{He}, \mathrm{CH}_{4}, \mathrm{O}_{2}, \mathrm{H}_{2}$, and $\mathrm{CO}$ using $\mathrm{Ar}$ as carrier, and a PPU column for $\mathrm{CO}_{2}$ as well as the three $\mathrm{C}_{2}$ compounds $\mathrm{C}_{2} \mathrm{H}_{6}, \mathrm{C}_{2} \mathrm{H}_{4}$ and $\mathrm{C}_{2} \mathrm{H}_{2}$ - with $\mathrm{He}$ as carrier. $\mathrm{H}_{2} \mathrm{O}$ was removed from the gas stream before entering the gas chromatograph with a membrane particulate/water filter (Genie 170 from A+ corporation), since the micro-GC has to be operated below $100{ }^{\circ} \mathrm{C}$ in order to separate $\mathrm{He}$ and $\mathrm{H}_{2}$. Consequently, water has to be calculated from the oxygen balance. All gases were calibrated against the internal standard prior to the experiment. On yet another column, $\mathrm{C}_{3} \mathrm{H}_{8}$ and $\mathrm{C}_{3} \mathrm{H}_{6}$ were detected but these gases were not calibrated. The experimental error originates mainly from the mass flow controllers with approximately $2 \%$ per gas species for a typical flow rate used $(0.1 \%$ of max. value $+0.5 \%$ of current value). The overall error of the gas-chromatograph is better than $1 \%$. The carbon and hydrogen balances close to more than $95 \%$, although minor species such as oxygenates were not calibrated.

\subsection{Fiber-Optic LIF Detection of $\mathrm{CH}_{2} \mathrm{O}$}

Formaldehyde $\left(\mathrm{CH}_{2} \mathrm{O}\right)$ is an important reaction intermediate in hydrocarbon oxidation. In combustion environments it can be observed in the preheating zone upstream the flame front. Under partial oxidation conditions, it is a major intermediate in the undesired $\mathrm{CO}$ pathway $[8,12]$, which will also be seen in Section 4.3.

In order to quantify $\mathrm{CH}_{2} \mathrm{O}$ concentrations experimentally, the extracted gas sample has to be heated so that $\mathrm{CH}_{2} \mathrm{O}$ does not condense along with water in the tubing. However, such heating is not always practical; indeed, the micro-GC used in this experiments requires water (and in turn $\mathrm{CH}_{2} \mathrm{O}$ ) to be removed from the gas sample before entering the GC. Alternatively, in situ Laser-Induced Fluorescence (LIF) constitutes a sensitive optical technique for $\mathrm{CH}_{2} \mathrm{O}$ detection. Even though this approach 


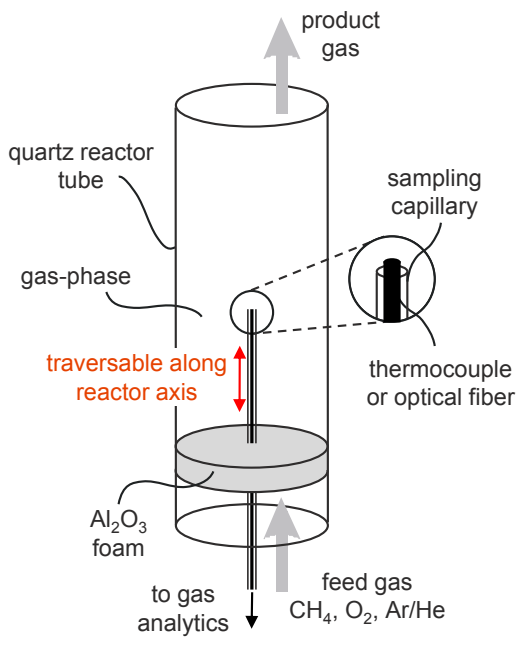

Figure 1: Reactor design. The electrical furnace enclosing the reactor is omitted for clarity.

is rather intricate and involved, it has to be pointed out that LIF may also be applicable to species which cannot be extractively sampled (such as radical species). Therefore, in the context of this study, the LIF study has to be regarded as a proof-ofconcept for setups in which conventional optical access is excluded.

Recently, we demonstrated the use of a novel technique permitting LIF detection in harsh environments using a single bidirectional optical fiber probe [10]. Since the reactor does not provide optical view-ports advantage is taken of the fact that the sampling capillary may (alternatively to the thermocouple) accommodate an optical fiber and thus provides optical access (magnification in Figure 1). Figure 2 shows the setup adapted for bidirectional coupling of the excitation laser and fluorescence detection using an optical fiber. $1 \mathrm{~mJ} /$ pulse of the third harmonic of a Q-switched Nd:YAG laser (SpectraPhysics, Quanta-Ray PRO) are coupled into the fiber to excite the $4_{0}^{1}$ band (i. e. the out-of-plane bending vibration) of the $\mathrm{CH}_{2} \mathrm{O} \mathrm{A}^{1} \mathrm{~A}_{2} \leftarrow \mathrm{X}^{1} \mathrm{~A}_{1}$ transition around $355 \mathrm{~nm}$. The laser line was measured with a grating spectrometer and found at $28183.46 \pm 0.10 \mathrm{~cm}^{-1}$ with a FWHM of $1.8 \mathrm{~cm}^{-1}$. To prevent optical damage of the fiber's end-face a micro-lens array (MLA in Figure 2) serves to homogenize the focal beam waist. Fluorescence is excited in the detection volume (DV) at the tip of the fiber and emitted isotropically so that a portion is again captured by the fiber. The signal is transmitted by the long-pass dichroic mirror (DM) and analyzed in a fiber-coupled spectrometer (SP). Strong Fresnel reflections of the laser-line and low wavenumber Raman scattering of the fiber are suppressed by an additional GG395 Schott glass filter. Since the CCD camera does not allow fast gating 100 shots are accumulated on the chip before reading out the spectrum. The average pulse energy is monitored using a power-meter $(\mathrm{P})$.

Step-index multimode fibers made of fused silica $\left(\mathrm{SiO}_{2}\right)$ with fluorine-doped claddings are commercially available. Be-

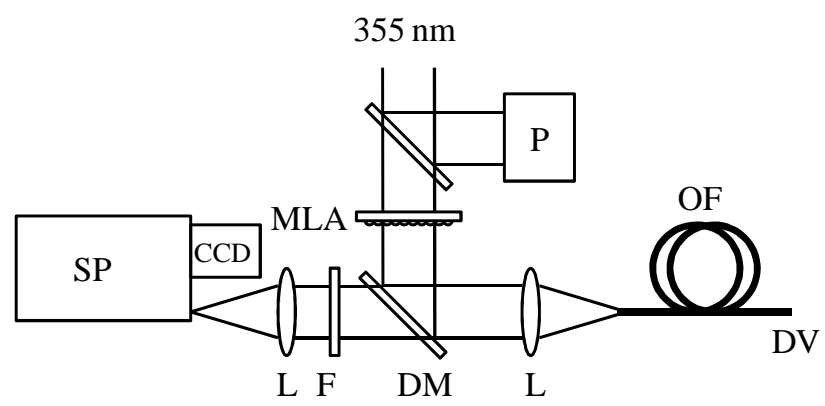

Figure 2: Schematic representation of the optical setup for bidirectional fiber coupling and fluorescence detection: DM dichroic (longpass) mirror, L lens, MLA micro-lens array, P power-meter, OF optical fiber, F glass filter, SP spectrometer, DV detection volume.

ing high-temperature resistive, at the same time they posses high damage threshold intensities thus being suitable for UV laser transmission. There are two types of fused-silica fibers, characterized by their $\mathrm{OH}$-content originating from the manufacturing process, commonly referred to as high-OH and low$\mathrm{OH}$. The fiber material's inherent, fabrication-induced impurities and defects may lead to undesired fluorescence, additional Raman bands, color-center formation, and photodegradation effects $[13,14,15,16]$. Stimulated Raman scattering and nonlinear effects become important only for long fibers or higher laser intensities [15]. Low-OH fibers are prone to strong broadband fluorescence at $355 \mathrm{~nm}$ excitation, thereby rendering them inappropriate for the current application. High-OH fibers show better UV-transmission characteristics, and it has been shown that the back-scattering spectra of high-OH fibers are characterized by the Raman signature of vitreous fused silica featuring phonon and defect bands at wavenumbers $<1200 \mathrm{~cm}^{-1}$, as well as a dominant peak around $409 \mathrm{~nm}$ which is to be attributed to the Raman band of the $\mathrm{OH}$-groups stretching mode (Raman shift $\sim 3700 \mathrm{~cm}^{-1}$ ), see Figure 3 and reference [10]. No spectral features are observed at longer wavelengths, so that this spectral window may be used to detect the $\mathrm{CH}_{2} \mathrm{O}$ fluorescence signal (inset in Figure 3).

It is necessary to comment on the spatial resolution of the fiber-LIF technique. In the following we present an analytical expression for the intensity and collection efficiency distribution at the fiber tip and derive an instrumental function that will be used later in the profile measurements. First, recall that an expression for the number of fluorescence photons $N_{\text {ph }}$ generated upon pulsed laser-excitation in the linear regime is given by

$$
N_{\mathrm{ph}}=\frac{B_{12} I_{v} \tau}{c} n V f_{\mathrm{B}} A_{21} \tau_{\mathrm{eff}} \frac{\Omega}{4 \pi}
$$

where for simplicity a two-level system is assumed, and $B_{12}$ is the Einstein coefficient of absorption (in $\mathrm{m}^{3} \mathrm{~Hz} \mathrm{~J}^{-1} \mathrm{~s}^{-1}$ ), $I_{v}$ is the spectral irradiance of the laser (in $\mathrm{W} \mathrm{m}^{-2} \mathrm{~Hz}^{-1}$ ), $\tau$ is the pulse length (in s), $c$ the speed of light, $n$ is the number density of the probed molecule (in $\mathrm{m}^{-3}$ ), $V$ is the detection volume (in $\left.\mathrm{m}^{3}\right), f_{\mathrm{B}}$ is the fraction of molecules in the rovibronic level being excited, $A_{21}=1 / \tau_{\text {rad }}$ is the Einstein coefficient for spontaneous emission (in $\mathrm{s}^{-1}$ ) with radiative lifetime $\tau_{\text {rad }}, \tau_{\text {eff }}$ (in $s$ ) is the 


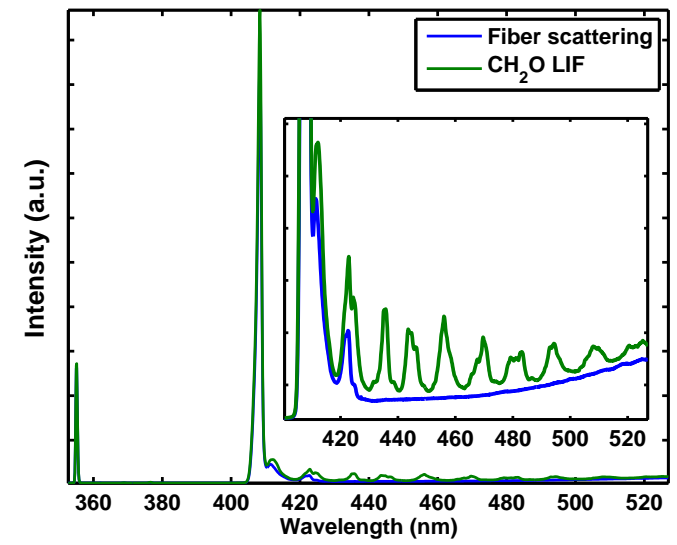

Figure 3: Backscattering spectrum of the optical high-OH fiber (blue) and ex situ $\mathrm{CH}_{2} \mathrm{O}$ laser-induced fluorescence spectrum acquired through the fiber (green). The strong peak at $409 \mathrm{~nm}$ is attributed to the fiber's OH-stretch Raman peak $\left(\sim 3700 \mathrm{~cm}^{-1}\right)$. The inset clearly shows the characteristic $\mathrm{CH}_{2} \mathrm{O}$ fluorescence superimposed on the fiber's Raman feature. The residue of the $355 \mathrm{~nm}$ laser line is seen while the spectral region up to $405 \mathrm{~nm}$ is filtered out by the dichroic mirror.

effective lifetime of the laser excited state accounting for nonradiative decay (quenching and predissociation), and $\Omega$ is the collection solid angle.

Equation (1) holds for a differential volume $d V$ and hence the total number of fluorescence photons collected for an arbitrary optical system is found by spatial integration

$$
N_{\mathrm{ph}}=\int_{V} d N_{\mathrm{ph}}=\int_{V} \frac{\partial N_{\mathrm{ph}}}{\partial V} d V
$$

where $\partial N_{\mathrm{ph}} / \partial V=B_{12} I_{v} \tau c^{-1} n f_{\mathrm{B}} A_{21} \tau_{\text {eff }}(\Omega / 4 \pi)$ is readily found from Equation (1). For convenience we only consider the irradiance $I$ instead of the spectral quantity $I_{v}$ in what follows. In a chemically homogeneous environment the only parameters showing a spatial dependence are $I(\vec{x})$ and $\Omega(\vec{x}) / 4 \pi$. It is convenient to assume cylindrical coordinates $\vec{x}(r, \varphi, z)$ so that we can define the detection efficiency

$$
\Gamma:=\int_{V} I(\vec{x}) \frac{\Omega(\vec{x})}{4 \pi} d \varphi r d r d z
$$

as a quantitative measure for the number of collected photons for different optical setups.

Neglecting absorption and saturation in the present derivation, $I(\vec{x})$ and $\Omega(\vec{x})$ follow from purely geometrical considerations. This is most conveniently understood by referring to Figure 4. Figure 4 (a) shows the radiation field $I(\vec{x})$ in cylindrical coordinates, which is in a first approximation deduced in terms of a $r^{-2}$ law. The irradiance distribution $I(\vec{x})$ is normalized by the laser power $P$, resulting in units $\mathrm{m}^{-2}$. On the other hand the solid angle of an arbitrary surface $S$ seen from a point $\vec{x}$ in space may be defined as

$$
\Omega(\vec{x})=\int_{S\left(\overrightarrow{x^{\prime}}\right)} \frac{\vec{X} / X \cdot \vec{n}_{S} d S}{X^{2}} .
$$

The integration is performed over $S\left(\overrightarrow{x^{\prime}}\right)$ where $\vec{n}_{S}=\vec{n}_{S}\left(\overrightarrow{x^{\prime}}\right)$ denotes the surface normal unit vector of the surface element $d S$ at position $\overrightarrow{x^{\prime}}$ and $\vec{X}:=\vec{x}-\overrightarrow{x^{\prime}}$. The distance vector $\vec{X}$ may also be interpreted as an optical ray from a point $\vec{x}$ to the surface element $d S\left(\overrightarrow{x^{\prime}}\right)$ and in the present consideration the surface $S$ obviously corresponds to the fiber end-face. Optical rays impinging on the surface at an angle which is greater than the critical acceptance angle of the optical fiber $\theta_{\mathrm{NA}}$ are reflected and cannot contribute to the effective collection solid angle. In mathematical terms this condition is expressed in terms of the angle $\angle\left(\vec{X}, \vec{n}_{S}\left(\overrightarrow{x^{\prime}}\right)\right)$, i.e. only if $\angle\left(\vec{X}, \vec{n}_{S}\left(\vec{x}^{\prime}\right)\right)<\theta_{\text {NA }}$ does the surface element $d \overrightarrow{x^{\prime}}$ contribute to the integration. Thus, we may rewrite Equation (4) as a conditional integral:

$$
\begin{aligned}
& \Omega(\vec{x})=\int_{S\left(\vec{x}^{\prime}\right)} \frac{\vec{X} / X \cdot \vec{n}_{S} d S}{X^{2}} . \\
& \angle\left(\vec{X}, \vec{n}_{S}\left(\vec{x}^{\prime}\right)\right)<\theta_{\mathrm{NA}}
\end{aligned}
$$

The result is shown in Figure 4 (b). Quantification of $I(\vec{x})$ and $\Omega(\vec{x})$ now allows for quantitative determination of the effective detection volume and the collection efficiency $\Gamma$ by means of integral (3). In particular, we will need

$$
\gamma(z):=\int_{0}^{2 \pi} d \varphi \int_{0}^{\infty} r d r I(\vec{x}) \frac{\Omega(\vec{x})}{4 \pi}
$$

which serves as the instrumental function for the optical fiber measurements presented here. $\gamma(z)$ is shown in Figure 4 (c) and will be used to deconvolute the measured LIF profiles (cf. Section 4.1).

\subsection{LIF Corrections}

The preceding discussion suggests that some comments are in order on the likelihood of saturation effects. From the intensity distribution in Figure 4 (a) it can be seen that the maximum value for the normalized intensity $I / P$ amounts to $8 \cdot 10^{6} \mathrm{~m}^{-2}$. Recalling a per-pulse-power $P$ of roughly $1 \mathrm{~mJ} / 10 \mathrm{~ns}=0.1 \mathrm{MW}$ and a linewidth of $1.8 \mathrm{~cm}^{-1}$, the spectral intensity is found to be on the order of $I_{v}=I / \Delta v=8 \cdot 10^{6} \mathrm{~m}^{-2} \times 0.1 \mathrm{MW} / 1.8 \mathrm{~cm}^{-1} \sim$ $10^{8} \mathrm{~W} / \mathrm{cm}^{2} \mathrm{~cm}^{-1}$. It is thus unlikely that saturation has occurred in the present experiment since this value is significantly lower than saturation intensities reported by other authors $[17,18]$. In retrospect, this justifies the linear regime assumption implied by Equation (1).

In view of making concentration profile measurements, two terms in Equation (1) need further consideration, namely the ro-vibrational Boltzmann population of the laser-coupled lower state and collisional quenching effects. Both will be discussed in the following paragraphs.

The portion of molecules in the lower laser-coupled state can be approximated assuming the molecule ensemble to be in thermodynamic equilibrium, i.e. the population distribution is described by the temperature-dependent Boltzmann fraction $f_{\mathrm{B}}(T)$. It may be calculated with a statistical mechanical formulation based on fundamental well-established molecular parameters. Boltzmann fractions may be evaluated independently for 


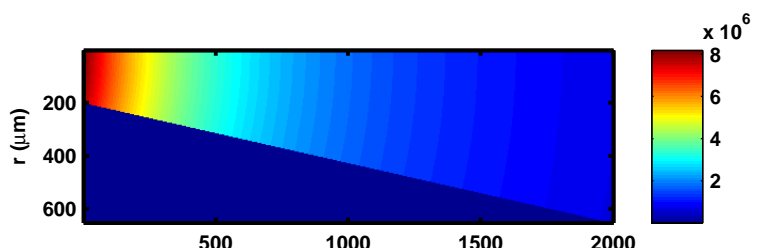

(a) Normalized irradiance field $I / P$ in $\mathrm{m}^{-2}$

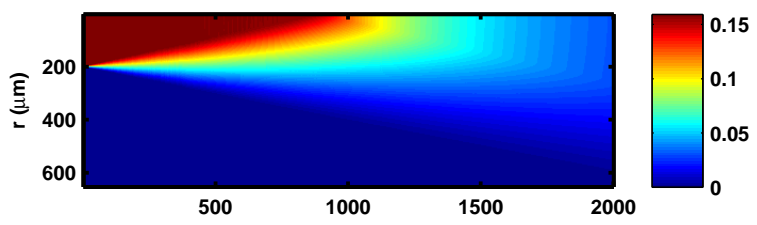

(b) Effective collection solid angle distribution $\Omega$ in sr

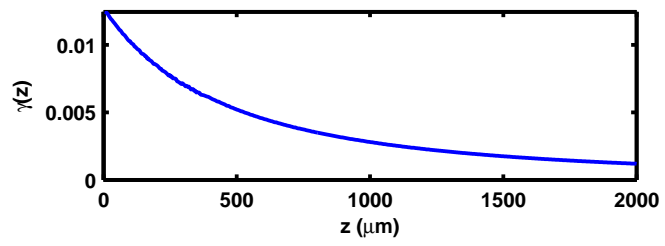

(c) Instrumental function $\gamma(z)$

Figure 4: (a) Normalized irradiance field $I / P$, and (b) effective collection solid angle distribution $\Omega$ in cylindrical coordinates ( $r$ and $z$ ). The instrumental function $\gamma(z)$ for the optical fiber probe is shown in subfigure (c). Fiber parameters: numerical aperture NA $=0.22$ and diameter $D_{\text {fiber }} 400 \mu \mathrm{m}$. the vibrational and rotational energy modes, $f_{B}(T)=f_{\text {vib }} f_{\text {rot }}$. The vibrational partition function $Z_{v i b}$ is expressed as a product over the vibrational energies $v_{i}$ [19],

$$
Z_{\mathrm{vib}}=\prod_{i=1}^{3 n-6}\left(1-\exp \frac{-h v_{i}}{k_{B} T}\right)^{-1}
$$

where the product for the planar $\mathrm{CH}_{2} \mathrm{O}$ is over the six vibrational normal modes with frequencies $v_{1}, \ldots, v_{6}[20,21]$. The population of the vibrational ground state reduces to $1 / Z_{\mathrm{vib}}$ and is plotted as a function of temperature in Figure 5 (a). In the temperature range relevant for this study $(600-1200 \mathrm{~K})$ the ratio of maximum to minimum value for $f_{\mathrm{vib}}$ is $\sim 2$; this ratio is also given in parenthesis in the figure and will serve as a measure for the temperature-sensitivity of the different correction terms. Subsequently, this ratio will be referred to as sensitivityfactor and will be determined for the rotational population variation as well as the quenching term so that a quantitative comparison of the terms is possible.

The rotational structure of the formaldehyde molecule is correctly represented by an asymmetric top. Fortunately the asymmetry is only slight, and therefore in good approximation its energy level structure can be described by a symmetrical top where an algebraic expression for the rotational states may be found. The rotational term values in the rigid rotor approximation of the prolate symmetrical top are

$$
E_{J, K} / h c=\widetilde{B} J(J+1)+(A-\widetilde{B}) K^{2}
$$

where $J$ is the total angular momentum quantum number, $K$ its component along the molecule's symmetry axis, $A>B>C$ are the rotational constants and $\widetilde{B}=1 / 2(B+C)[22,20]$. Due to the dense structure of the formaldehyde spectrum and the relatively broad excitation linewidth of the multimode laser, several transitions contribute [23]. From the tabulations provided by Dieke and Kistiakowsky it could be established that four transitions of the $p P$-branch are excited, and their line intensities are described by the Hönl-London formula for $\perp$ bands [22, 24]

$$
B_{J, K}^{p P}=\frac{(J+K-1)(J+K)}{J(2 J+1)}
$$

so that the overall absorption intensity is proportional to the weighted sum of the individual lines

$$
f_{\text {vib }} \sum_{\{J, K\}} B_{J, K}^{p P} \frac{g_{K J} \exp \frac{-E_{J K}}{k T}}{Q_{\text {rot }}}
$$

where $g_{K J}$ is the rotational-nuclear spin statistical weight for the state $\{J, K\}$ so that the latter term represents the Boltzmann fractions for the individual rotational states (Figure 5 (b)). Again, the sensitivity-factor of the rotational population temperaturedependence in the relevant temperature range is determined as the ratio of maximum to minimum value and amounts to $\sim 2$ (again given in parenthesis for each rotational state in the figure). The temperature dependence of the overall absorption over the relevant temperature range is plotted in Figure 5 (c). 
We note that both vibration and the rotation contribute comparably to the Boltzmann temperature-dependence and that the overall sensitivity-factor is roughly 4.

The effective lifetime of the laser excited state(-manifold) $\tau_{\text {eff }}=(A+Q)^{-1}$ is related of to the collisional quenching rate $Q$. The quenching rate $Q=\sum_{i} n_{i} \sigma_{i} v_{i}$ in turn is a function of composition $n_{i}$, the quenching cross-section $\sigma_{i}$ and the relative molecular velocity $v_{i}=f(T)$ of all possible collision partners. Though Harrington and Smyth [17] state that the Boltzmann dilution is by far the larger correction term, the body of literature of fundamental quenching parameters in the appropriate temperature, pressure and composition space is rather scarce. Several groups $[25,26,27,23,28]$ have measured effective fluorescence lifetimes $\tau_{\text {eff }}$ in flames and generally find a monotonically decreasing lifetime along the reaction coordinate, roughly described by a $T^{-1}$ relation. Correction for this effect effectively leads to a downstream shift of the measured $\mathrm{CH}_{2} \mathrm{O}$ profile with respect to the LIF signal. In those studies, ratios of maximum to minimum lifetimes and thus the sensitivity-factor to this correction term ranges between 2 - 3, while the temperature gradients spanned more than $1000 \mathrm{~K}$ accompanied by the drastic composition change characteristic for flames. With respect to the present experiment, the temperature gradient is smaller $(\sim 500 \mathrm{~K})$, and also the composition change is moderate due to the dominating methane content. It may thus be expected that the lifetime correction term here is on the same order or smaller and in first approximation may be described by a $\tau_{\text {eff }} \propto T^{-1}$ relation.

Summing up the preceding section, it is now possible to compare the effect of the two correction terms and it can be seen that the overall Boltzmann factor is indeed the larger contribution compared to the quenching term. The sensitivity to the latter can be expected to be smaller than 2 while the Boltzmann correction term sensitivity factor was roughly twice as large. While an expression for the Boltzmann variation has been derived (Figure 5 (c)), we will assume $\tau_{\text {eff }} \propto T^{-1}$ for the quenching effect; the influence of the correction terms on the measured profiles is discussed in Section 4.

\section{Kinetic Reactor Simulations}

The challenge in reacting flow simulations is to describe accurately the coupled transport and chemistry phenomena. The present section discusses two important aspects of the detailed chemical kinetic simulations performed: (i) reduction of the elementary kinetic mechanism as a prerequisite for computational feasibility, and (ii) comprehensive modeling of the flow reactor by means of detailed kinetic Computational Fluid Dynamics (CFD).

\subsection{Mechanism Reduction}

In a literature review of available detailed kinetic mechanisms for fuel-rich methane oxidation conditions characteristic for OCM - the study will be described in a forthcoming paper by the authors - it was found that the mechanism reported by Dooley et al. [29] performs most satisfactorily; this conclusion is drawn from the comparison of a set of experimental

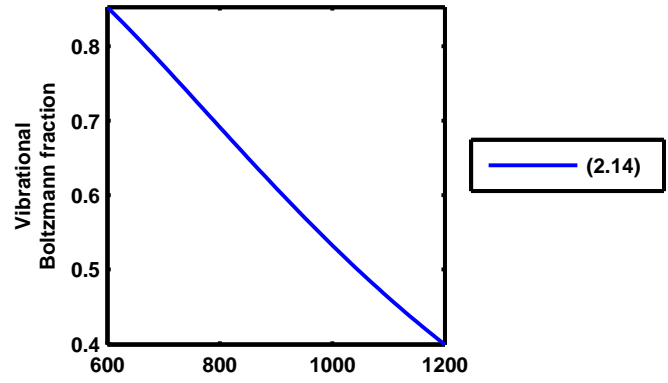

(a) Boltzmann population of the excited vibrational ground state $f_{\text {vib }}(T)$

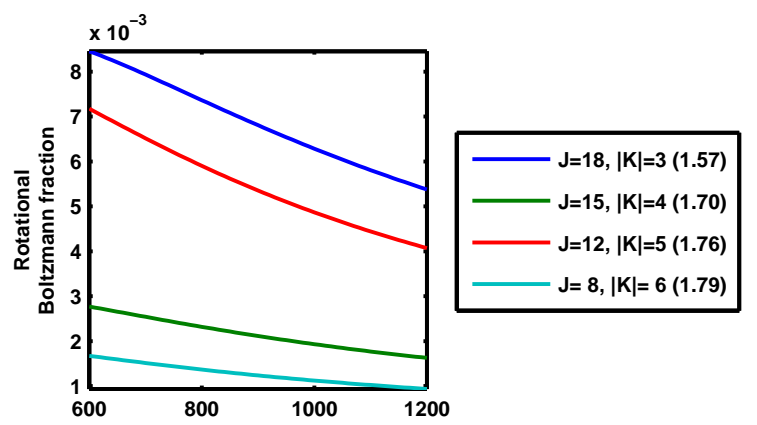

(b) Boltzmann population of rotational states $f_{\text {rot }}(T)$ contributing to the LIF signal

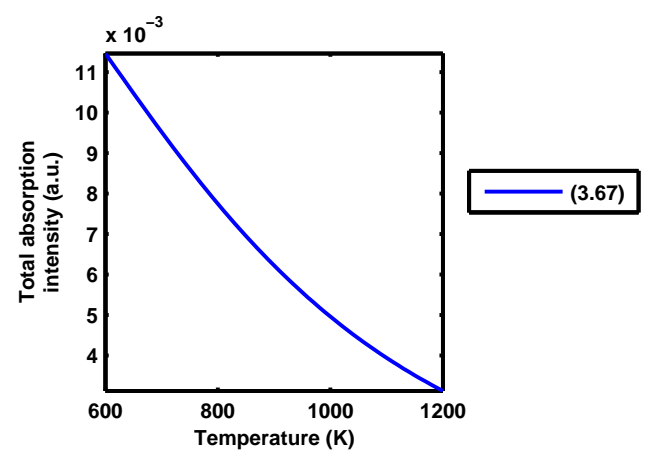

(c) Total absorption intensity as in equation (10)

Figure 5: Temperature dependence of the vibrational ground state population $f_{\text {vib }}(\mathrm{a})$, the rotational state population $f_{\text {rot }}(\mathrm{b})$, and total absorption intensity (c). As a measure for the correction effect the ratio of maximum to minimum values are given in parenthesis. 
reactor profiles to kinetic simulations. Therefore this mechanism was employed in the present investigation. It is a comprehensive kinetic mechanism including $\mathrm{H}_{2}, \mathrm{C}_{1}, \mathrm{C}_{2}, \mathrm{C}_{3}$ and $\mathrm{C}_{4}$ oxidation chemistry. Broadly speaking, it consists of two submechanisms: a small-molecule mechanisms by $\mathrm{Li}$ et al. [30] for synthesis gas combustion, and a larger mechanism for $\mathrm{C}_{1}$ $\mathrm{C}_{4}$ oxidation and pyrolysis by Healy et al. [31]. The dependence of many elementary steps on pressure is considered and third-body efficiencies of many species are included.

Mechanism reduction is often indispensable in CFD simulations of chemically reacting flow. In fact, the commercial CFD software used in the present work, FLUENT, is hard-coded for a maximum of 50 species, and the mechanism by Dooley et al. has nearly 300 species. Fortunately, the vast majority of those species are irrelevant for fuel-rich methane oxidation under conditions relevant to this study, due to the consecutive nature of the reaction. From a chemical perspective, the 50species limit is completely arbitrary; nonetheless, in order to determine the "50 most important species" for the present problem, the mechanism was reduced as follows. First, the experimental conditions were simulated using the Plug-Flow Reactor model (PFR) implemented in $\mathrm{CHEMKIN}^{2}$, since this model allows for first-order sensitivity analysis of the species with respect to the rate coefficients. Sensitivity analysis was performed for each of the eight target species that were quantitatively detected: $\mathrm{CH}_{4}, \mathrm{O}_{2}, \mathrm{H}_{2}, \mathrm{H}_{2} \mathrm{O}, \mathrm{CO}, \mathrm{CO}_{2}, \mathrm{C}_{2} \mathrm{H}_{6}$ and $\mathrm{C}_{2} \mathrm{H}_{4}$. For each of these species, the reactions were sorted according to the absolute value of the sensitivity coefficients (in descending order). Next, each species in the mechanism was ranked according to its position in the list of sorted reactions; for example, each species in the first reaction was given a score of 1 , and each species in the second reaction was given a score of 2 (assuming that those species were not also in the first reaction). Once this process had been repeated for all target species, the scores for all the species in the mechanism were summed, and the 49 species with the lowest scores were retained. Ar was forced to be the 50th species, since it served as internal standard in the experiments but does not occur in any reaction. Another reason for using Ar as 50th species was that all numerical rounding errors as well as errors from the mixture averaged diffusion treatment were lumped in the Ar mass fraction. The process was repeated for $\mathrm{CH}_{4} / \mathrm{O}_{2}$ feed ratios ranging from 4, 8 and 16, temperatures at 700 and $1100 \mathrm{~K}$, and pressures of 1 and 8 bar. An alternative approach is to use the absolute flux through each reaction, rather than its sensitivity coefficient. The process above was repeated using the flux-based approach. The two methods were in close agreement regarding the most important species, with the top 41 species being identical. Where the two approaches differed, the sensitivitybased approach tended to favor smaller oxygenates, whereas the flux-based approach tended favor larger unsaturated hydrocarbons. A detailed comparison of the two reduction methods with other more established mechanism reduction methods is beyond the scope of the present work but will be the subject of

${ }^{2}$ REACTION DESIGN(C) CHEMKIN 10111 a forthcoming manuscript. For simplicity, we have adopted the sensitivity-based method for the remainder of this work. The reduced mechanism is appended as Supplemental Material, with the different species between the two methods highlighted.

Using the Cylindrical Shear-Flow Reactor model (CSFR) in CHEMKIN the appropriateness of the mechanism reduction was verified. Shown in Figure 6 is the comparison between the complete and the reduced mechanism based on the CSFR center-line profiles (solid and dashed line respectively). The mechanism reduction results in a slight upstream shift of the profiles, but all species concentrations are reproduced within a minor error. Although the 50-species limit is arbitrary, it can be stated that the disadvantage of the mechanism reduction is outweighed by the benefits of the detailed CFD simulations as will be outlined below.

\subsection{Reactor Modeling}

The complete set of steady-state, laminar Navier-Stokes equations was solved using the finite-volume implementation of the FLUENT software package ${ }^{3}$ with the CHEMKIN-CFD package for detailed kinetics ${ }^{4}$. The two-dimensional axisymmetric simulation domain comprises the reacting fluid zone as well as the silica reactor walls and the sampling capillary. The fluid physical properties of the individual gas-phase species are calculated based on kinetic theory expression, and polynomial coefficients for the temperature-dependent thermal conductivity of the fused-silica bodies were taken from the literature [32]. Diffusion was modeled based on the mixture-averaged approach. The only boundary conditions imposed are the fluid inlet conditions and the outer wall temperature. Inlet flow properties are assumed constant over the radius, which is experimentally assured by the foam at the flow inlet. Note that the sampling capillary imposes another no-slip condition in the reactor center, which leads to an annular flow profile. The computational domain was meshed using rectangular cells of uniform dimensions. Throughout the computational process the grid spacing of the fluid zone was gradually reduced down to $0.1 \mathrm{~mm}$ until no significant changes in the species contours could be observed. In the radial direction the fused-silica reactor wall was meshed with $1 \mathrm{~mm}$ spacing while the central capillary was radially subdivided into 2 equally sized cells. A steady-state solution was attained with residuals below $10^{-5}$.

The Reynolds number, $R e$, is on the order of 100 so that laminar flow conditions can be assumed. The Péclet numbers for energy and mass transport $P e_{T}=L u / \alpha$ and $P e_{i}=L u / D_{i}$ are on the order of 50 and 20 , respectively. Here, $L$ is the characteristic length given by the extension of reaction zone $(\sim 10 \mathrm{~mm}), u$ the annular flow velocity $(\sim 0.1 \mathrm{~m} / \mathrm{s}), \alpha$ the thermal diffusivity $\left(\sim 2 \cdot 10^{-5} \mathrm{~m}^{2} / \mathrm{s}\right)$, and $D_{i}$ represents the diffusion coefficients of species $i\left(\sim 5 \cdot 10^{-5} \mathrm{~m}^{2} / \mathrm{s}\right.$ for $\left.\mathrm{H}_{2}\right)$. The Péclet number derives from dimensional analysis and compares the convective and diffusive terms in the energy and species' mass conservation equation. If the Péclet number is substantially greater

${ }^{3}$ ANSYS(C) Academic Research CFD, Release 14.5

${ }^{4}$ REACTION DESIGN@ CHEMKIN-CFD for FLUENT Module 20112 
than unity, then it is assumed that axial diffusion is negligible compared to convection and may be omitted from the transport equations. Neglecting the diffusion term changes the system of partial differential equations from elliptic to parabolic, which has substantial implications for numerical solution. For the present problem of chemically reacting flow in a tube, this simplification is known as the boundary-layer model [33], and it is implemented in CHEMKIN as the Cylindrical Shear-Flow Model (CSFR)[34]. Using the boundary-layer model has the advantage that detailed kinetics can be implemented at reasonable computational costs, whereas full Navier-Stokes simulations with a comprehensive kinetic mechanism easily become computationally intractable on a workstation.

However, for laminar flow with a parabolic velocity profile, reliance on the Péclet number can be misleading. Due to the no-slip condition the local Péclet number is smaller than unity close to the wall. In order to scrutinize the impact of the simplifying assumptions made by the CSFR model, CHEMKIN CSFR simulations were compared with a complete NavierStokes simulation in FLUENT for identical geometrical and thermal boundary constraints, i.e. a parabolic flow with constant boundary temperature. Figure 6 shows the respective centerline profiles (dashed line CHEMKIN CSFR and dotted line FLUENT). It is seen, that the CSFR is an excellent approximation to the full Navier-Stokes solution for the conditions of interest, but the center-line profiles for the full solution are shifted upstream compared to the CSFR model, while the gradients themselves do not change. This result can be rationalized as follows: The fact that the CSFR assumption breaks down close to the wall leads to the axial shift. The radical chain branching reactions are thermally initiated, and these reactions first occur closest to the walls. Subsequently, diffusive (radical) species generated within the boundary layer can diffuse back upstream, which causes the profile shift. The fact that the profile gradients are conserved reflects that diffusive transport in the reactor center, where the flow velocity is higher, is negligible, as implied by the Péclet numbers stated above. If diffusion effects were strong one would expect dispersion of the profile gradients. These observation is analogous to findings in the context of simulations of a honeycomb channel in a catalytic combustion study [35].

Though we have seen that the CSFR model represents an excellent approximation to the the full Navier-Stokes solution in an empty tube, it is expected that its shortcomings will become more important when the full reactor geometry, including reactor wall and the second no-slip conditions due to the sampling capillary, are introduced into the model, in addition to the diffusion effect. Generally, profile shifts of 5-10 mm were observed under our conditions, while the profile gradients were retained.

\section{Results and Discussion}

\section{1. $\mathrm{CH}_{2} \mathrm{O}$ LIF Profile Measurements}

Figure 7 shows fluorescence spectra upon $355 \mathrm{~nm}$ excitation with the optical probe anchored at different axial positions in the reactor. The spectra were corrected for the fiber

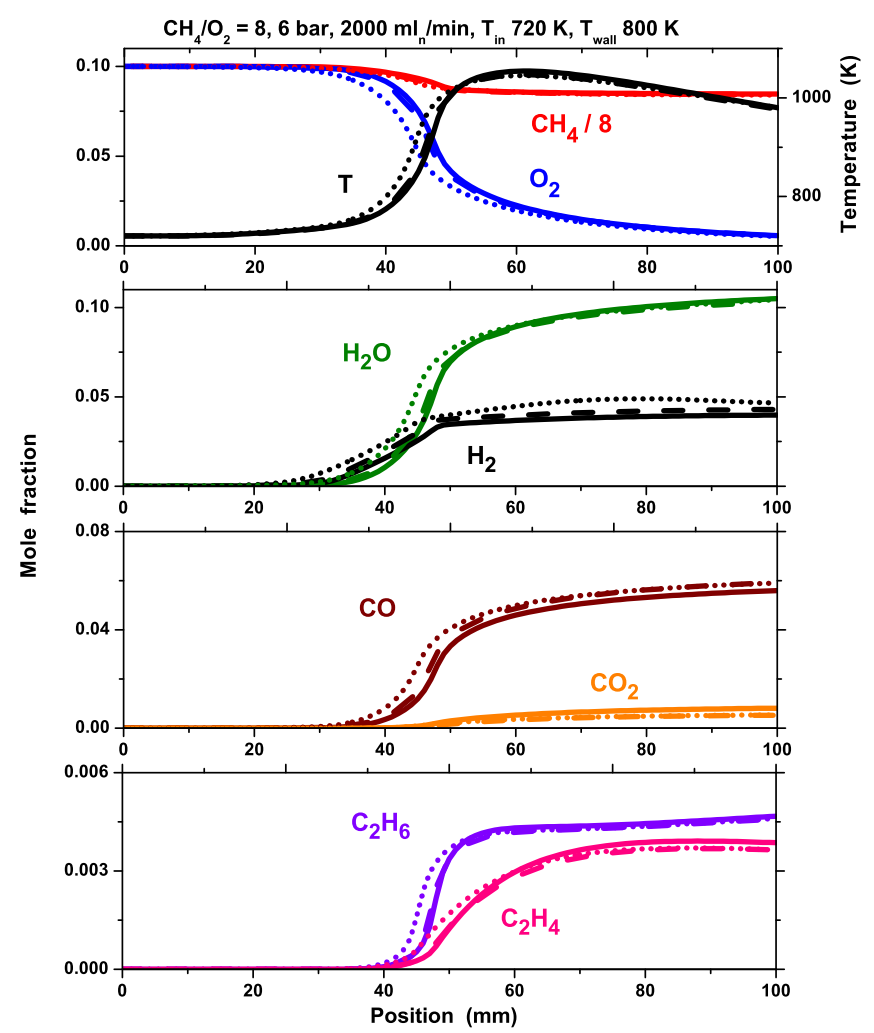

Figure 6: Simulated temperature and speciation profiles. The solid and dashed lines are CHEMKIN CSFR simulation results using the complete and the reduced Dooley mechanism respectively; the dotted line is the FLUENT CFD simulation also based on the reduced Dooley mechanism. Conditions correspond to a $\mathrm{CH}_{4} / \mathrm{O}_{2}$ feed ratio of 8,6 bar pressure, and a total flow rate of $2000 \mathrm{mln} / \mathrm{min}$ in a tubular flow reactor with a constant boundary temperature of $800 \mathrm{~K}$ 
background. Comparison with the reference spectrum, which was taken in the vapor phase over a formalin solution (dotted line), provides confirmation of formaldehyde detection. The vibrational bands observed are attributed to transitions in the $\mathrm{CO}$ stretch and the out-of-plane bending vibrations, designated $2^{0}{ }_{n}{ }^{1}{ }_{m}(\mathrm{n}, \mathrm{m}=0,1,2, \ldots)$ with respect to the notation by Clouthier and Ramsay [20]. At the same time a changing broadband background is noticeable, the origin of which could not be unambiguously identified but might be attributed to fluorescence of polyaromatic hydrocarbons (PAH). It was shown by Metz et al. [36] and Brackmann et al. [37] that the spectral features of $\mathrm{CH}_{2} \mathrm{O}$ fluorescence do not change significantly with temperature or pressure. Therefore, in order to extract the desired concentration information from the spectra a least-square fitting analysis was applied, in which the experimental spectra $s(\lambda)$ were fitted to the superposition of the scaled reference spectrum $r(\lambda)$ and a third order polynomial $p_{3}(\lambda)$ representing the broadband background,

$$
s(\lambda)=C r(\lambda)+p_{3}(\lambda)
$$

A good match of the fitting procedure is attained, which is shown in the inset of Figure 7 . The scaling constant $C$ is taking as a measure for the $\mathrm{CH}_{2} \mathrm{O}$ concentration and the resulting LIF profile as function of the fiber tip position is shown in Figure 8.

As discussed in Section 2.2, the LIF signal is integrated over a finite volume ahead of the fiber tip. Mathematically speaking the LIF signal is a convolution of the $\mathrm{CH}_{2} \mathrm{O}$ concentration and the instrumental function of the LIF fiber probe. In fact, the instrumental function was derived analytically above and is given by $\gamma(z)$ (Figure 4 (c)). The deconvolution was performed, the resulting profile of which is presented in Figure 8. As expected, the $\mathrm{CH}_{2} \mathrm{O}$ profile is shifted downstream with respect to the raw LIF data.

As outlined in Section 2.3, validation of the $\mathrm{CH}_{2} \mathrm{O}$ profiles requires correction for the temperature-dependent Boltzmann fraction and collisional quenching. An analytic expression was derived for the former whereas the impact of the latter can in first approximation be described by a $\tau_{\text {eff }} \propto T^{-1}$ relation. Rather than correcting the measured signal, which would in turn require temperature measurements and introduce additional statistical or systematic experimental errors, the simulation results were corrected so as to yield a computed fluorescence signal, an approach proposed by Connelly et al. [38]. In anticipation of the simulation results the experimental $\mathrm{CH}_{2} \mathrm{O}$ LIF profile along with the $\mathrm{CH}_{2} \mathrm{O}$ profile is presented in Figure 8. The effect of both the Boltzmann and quenching correction can be seen. It is found that both correction terms leads to significant shifting and contour change of the profiles. However, as will be seen in the next section, on the global scale of reactor profile measurements the effect is of minor importance and certainly not to be held responsible for the observed offset between experimental and numerical data.

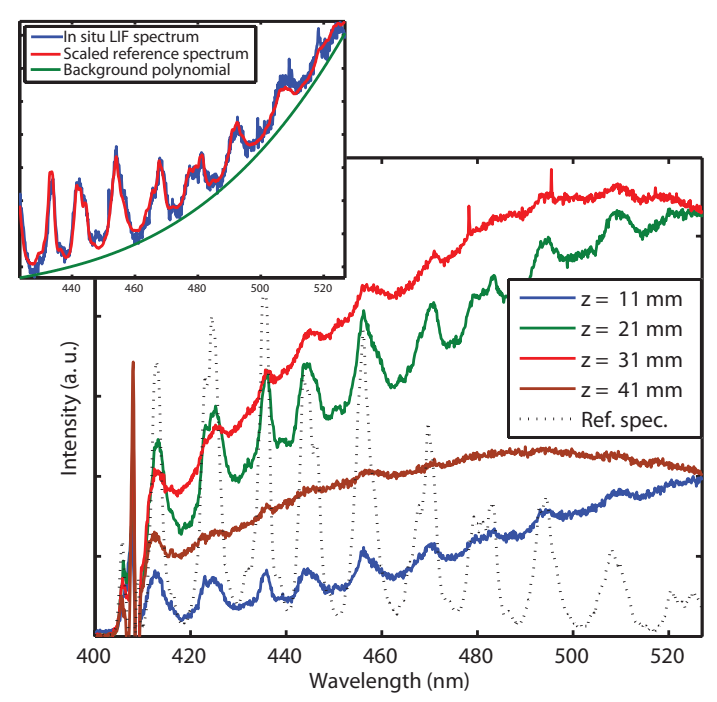

Figure 7: In situ $\mathrm{CH}_{2} \mathrm{O}$ LIF spectra at different axial positions in the reactor. An ex situ $\mathrm{CH}_{2} \mathrm{O}$ spectrum is also depicted as reference (dotted line), clearly showing the characteristic $\mathrm{CH}_{2} \mathrm{O}$ vibrational features in the in situ spectra. The inlet shows the polynomial fitting of the broadband background which allows isolation of the $\mathrm{CH}_{2} \mathrm{O}$ signal.

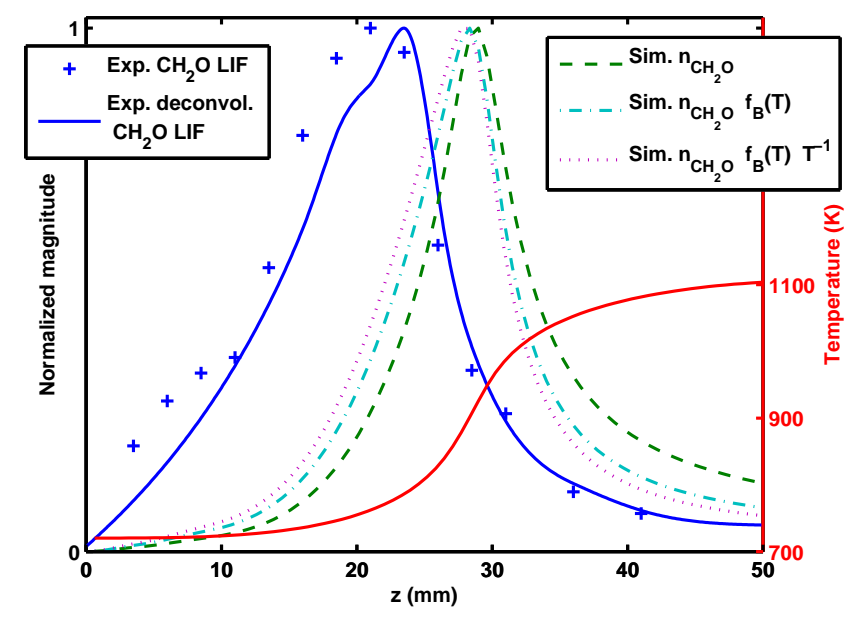

Figure 8: Deconvolution of LIF profile and impact of Boltzmann and quenching correction on $\mathrm{CH}_{2} \mathrm{O}$ profile. 


\subsection{Species Profiles}

A set of experiments was performed by varying pressure (1 - 8 bar), composition $\left(\mathrm{CH}_{4} / \mathrm{O}_{2} 4\right.$ - 16) and flow rate (2000 - $4000 \mathrm{ml}_{n} / \mathrm{min}$ ); the findings were all in qualitative agreement so that general features of the reaction could be isolated ${ }^{5}$. Here we present a representative experiment that was performed with a $\mathrm{CH}_{4} / \mathrm{O}_{2}$ feed ratio of $8(\mathrm{C} / \mathrm{O}$ atom ratio of 4$)$, at 6 bar pressure and a flow rate of $2000 \mathrm{ml}_{n} / \mathrm{min}$. A $10 \%$ dilution by an Argon/Helium mixture as internal standard for the gas analysis was used, and the ceramic oven enclosing the reactor tube was set to $970 \mathrm{~K}$. The residence time amounts to roughly 2 seconds.

The outcome of the numerical simulation is depicted in Figure 9, where contour plots of velocity, temperature as well as the investigated species are shown. The boundary conditions were defined such that the reactants, methane and oxygen, enter from the left at uniform temperature and flow velocity. In each plot, the thin solid and dashed white lines correspond to the 0.099 and 0.09 isolines of the $\mathrm{O}_{2}$ mole fraction, respectively, i.e. 1 and $10 \%$ conversion; these lines help indicate qualitatively the reaction onset. The following qualitative observation can be made from the contour plots: First, it is seen that an annular velocity profile develops due to the dual no-slip boundary condition at the wall and the fused silica capillary at the center. Second, the wall exhibits an inhomogeneous temperature distribution ranging from $\sim 900$ to $980 \mathrm{~K}$ - which underlines the importance of heat transport within the wall. Once the exothermic chemistry has begun, it dominates the heat release in the flow, and the reactor wall becomes a heat sink. Third, it is instructive to observe the onset of reaction indicated by the 0.099 and 0.09 $\mathrm{O}_{2}$ mole fraction contour lines. Close to the wall, the temperature between the two contour lines is between 910 and $940 \mathrm{~K}$, whereas at the center of the reactor oxygen consumption starts at a much lower temperature of $730-770 \mathrm{~K}$. This suggests that the reaction first ignites thermally close to the wall due to external heating and only then the reaction diffuses radially into the reactor center. The centerline temperature profile is therefore not a good benchmark for the onset temperature of the reaction. Fourth, once the $\mathrm{O}_{2}$ mole fraction drops below roughly 0.02 , then the gradients for all other species become considerably less steep, and downstream of that point the overall composition changes only slightly. Lastly, the concentration profiles for $\mathrm{H}_{2}$ and $\mathrm{CH}_{2} \mathrm{O}$ stand out in particular. The $\mathrm{H}_{2}$ gradients are less pronounced, presumably due to its high diffusivity. The $\mathrm{CH}_{2} \mathrm{O}$ is unique in that it is clearly a reactive intermediate, with a concentration profile confined to a narrow region of peak oxidation.

The centerline profiles from the two-dimensional distributions are compared with the experimental data. The simulated profiles and experimental data are depicted in Figure 10. Globally, we observe the following trends in both experiment and simulation: Primary reaction products in order of abundance are $\mathrm{H}_{2} \mathrm{O}, \mathrm{CO}, \mathrm{H}_{2}$, and minor amounts of $\mathrm{CO}_{2}$. Formaldehyde

\footnotetext{
${ }^{5}$ The entire set of experimental results together with a literature review of available detailed kinetic mechanisms is going to be presented in a forthcoming report by the authors.
}

\begin{tabular}{cccc}
\hline $\begin{array}{c}\text { Molar } \\
\text { fractions }\end{array}$ & Experiment & Simulation & $\begin{array}{c}\text { Thermodynamic } \\
\text { Equilibrium }\end{array}$ \\
\hline \hline $\mathrm{CH}_{4}$ & 0.67 & 0.67 & 0.46 \\
$\mathrm{O}_{2}$ & 0.007 & 0.008 & 0 \\
$\mathrm{H}_{2} \mathrm{O}$ & 0.122 & 0.103 & 0.001 \\
$\mathrm{H}_{2}$ & 0.032 & 0.046 & 0.30 \\
$\mathrm{CO}$ & 0.049 & 0.055 & 0.15 \\
$\mathrm{CO}_{2}$ & 0.005 & 0.007 & 0.0006 \\
$\mathrm{C}_{2} \mathrm{H}_{6}$ & 0.011 & 0.004 & 0.0003 \\
$\mathrm{C}_{2} \mathrm{H}_{4}$ & 0.011 & 0.007 & 0.0002 \\
$\mathrm{C}_{2} \mathrm{H}_{2}$ & $\sim 6 \cdot 10^{-5}$ & $5 \cdot 10^{-5}$ & $2 \cdot 10^{-6}$ \\
$\mathrm{C}_{3} \mathrm{H}_{8}$ & $\sim 3 \cdot 10^{-4}$ & $8 \cdot 10^{-5}$ & $5 \cdot 10^{-7}$ \\
$\mathrm{C}_{3} \mathrm{H}_{6}$ & $\sim 1 \cdot 10^{-3}$ & $5 \cdot 10^{-4}$ & $4 \cdot 10^{-6}$ \\
\hline
\end{tabular}

Table 1: Molar fractions at reactor outlet of experiment and simulation in comparison to the thermodynamic equilibrium composition at $1100 \mathrm{~K}$. All species showing an equilibrium value above $10^{-6}$ as well as $\mathrm{C}_{3} \mathrm{H}_{8}$ are listed.

$\mathrm{CH}_{2} \mathrm{O}$ is formed as one of the primary products in the prereaction zone; being a reaction intermediate it is almost completely consumed subsequently. While $\mathrm{C}_{2} \mathrm{H}_{6}$ is produced predominantly by the direct coupling of two methyl radicals via the trimolecular reaction

$$
2 \mathrm{CH}_{3}+\mathrm{M} \rightarrow \mathrm{C}_{2} \mathrm{H}_{6}+\mathrm{M},
$$

$\mathrm{C}_{2} \mathrm{H}_{4}$ is only a secondary product formed by dehydrogenation of $\mathrm{C}_{2} \mathrm{H}_{6}$. Further dehydrogenation is minor, and therefore acetylene is formed only in trace amounts on the order of $\sim 6 \cdot 10^{-5}$. Though the $\mathrm{GC}$ was not calibrated for $\mathrm{C}_{3}$ species, we estimate that $\mathrm{C}_{3} \mathrm{H}_{6}$ and $\mathrm{C}_{3} \mathrm{H}_{8}$ were formed in amounts of approximately 0.001 and 0.0003 , respectively. Consumption of oxygen leads to a slowdown and eventually to an almost halt of the reaction. It is interesting to note that the exit composition is far from the composition predicted by thermodynamic equilibrium. The kinetic control provided by the self-induced oxygen exhaustion and the short residence time yields a mixture composition in an off-equilibrium state (cf. Table 1).

While experiment and simulation are in good agreement, it is now of interest to focus on the discrepancies between the two. It should be mentioned that the temperature measurements were not corrected for radiation, so the thermocouple reading may be biased by radiation heat exchange with the oven coils. But this effect is presumably only important when the gas temperature is low, such as at the reactor entrance. As soon as exothermic chemistry starts and the temperature rises, it dominates the temperature reading of the thermocouple. Generally, the temperature profile is in fair agreement with the simulation indicating that the global heat balance is conserved by the simulation. In the following, we will successively discuss causes that may contribute to the quantitative disagreement between the experiments and modeling. The discussion is based on the following three observations, i. e. differences in

- reaction onset,

- reaction gradients, and

- absolute concentrations.

The difference in reaction onset is manifested in an axial shift of the profiles, which is most evident in the shift of the 
formaldehyde peak concentration position. It bears mentioning that this problem is routinely encountered in flow reactor measurements [39]. Although "time-shifting" is an accepted practice when modeling flow-reactors (cf. to Supplementary Material of [39]), we have chosen not to do so so as to highlight the strengths and limitations of the current approach. The shift in reaction onset could be attributed to a combination of two possible effects. (i) In the simulations, the outer wall temperature was set equal to the oven temperature which was measured in each experiment. Using the oven temperature as boundary condition on the reactor tube is naturally an overestimate because the oven coils and the outer tube wall are not in thermal equilibrium. The actual boundary condition for the outer wall may hence be lower than assumed. Also, the uniform temperature boundary conditions imposed at the inlet can only be an approximation to the real inlet distributions where one may still find radial gradients despite the efficient heat-transfer inside the foam. (ii) Radiative heat transfer was not included in the simulation, though methane features infra-red absorption bands. Since the inlet gas composition is $80 \%$ methane, radiative heat transfer from the oven coils to methane could have a non-negligible heating effect. In the optically thin approximation, Bhattacharjee and Grosshandler [40] have introduced a dimensionless quantity (similar to the Reynolds and Péclet number) which compares radiative and convective heat transport,

$$
\frac{\sigma a\left(T_{\mathrm{wall}}^{4}-T^{4}\right)}{\rho u c_{p} / L\left(T_{\mathrm{out}}-T_{\mathrm{in}}\right)} .
$$

Here, $\sigma$ is the Stefan-Boltzmann constant, $a$ is the absorption coefficient of the gas [41], $T_{\text {wall }}$ and $T$ are the wall and gas temperatures, respectively, $\rho$ is the fluid density, $u$ and $L$ are the characteristic velocity and length scale, and $T_{\text {out }}-T_{\text {in }}$ is the characteristic fluid temperature gradient. If global characteristic scales are considered this value is of order 0.1 , but again the dimensional analysis may not be valid locally so that radiative heat transport may still have an influence. However, the effect is pronounced only in regions where the fluid temperature $T$ is much lower than the wall temperature $T_{\text {wall }}$ such as at the reactor inlet and close to walls where the velocity is vanishing. Accordingly, it has been observed in accompanying experiments that the disagreement of the reaction onset becomes more pronounced the longer the non-reacting thermal entrance region of the flow is. In these cases the heat balance error accumulates up to the point of reaction onset and leads to more pronounced relative shifts of experimental and simulated profiles. However, once the ignition temperature is reached the heat generation due to the reaction dominates the energy balance and the temperature difference between fluid and "radiating" wall is then relatively small, which justifies comparison of experiment and simulation despite this shortcoming of the model.

The simulated reaction gradients are steeper than those observed in the experiments. There are three possible explanations: (i) In the experiment, the gas mixture is sampled over a finite volume. But since the sampling volume is much smaller than the observed gradients, this effect can be excluded from causing the shallower gradients. (ii) A second consideration is the modeling of molecular transport within the gas phase. The present work uses the more computationally feasible mixtureaverage approach. Although a more rigorous multi-component model could change the gradients, it is unlikely that this effect would be major. (iii) The third explanation for the observed differences is attributed to the mechanism itself. Since the mechanism reduction did not show a significant difference in reaction gradients, the differences would imply generally overpredicted rates by the mechanism.

The absolute concentrations of the major species are in good agreement. $\mathrm{H}_{2} \mathrm{O}$ is somewhat underpredicted and $\mathrm{H}_{2}$ is slightly overestimated by the simulation, while both $\mathrm{CO}$ and $\mathrm{CO}_{2}$ are slightly overpredicted. However, the discrepancy for the concentrations of the $\mathrm{C}_{2}$ species is considerably more significant. The primary coupling product $\mathrm{C}_{2} \mathrm{H}_{6}$ is underestimated by a factor of three, while $\mathrm{C}_{2} \mathrm{H}_{4}$ is underpredicted by roughly one-third of the experimental value. As was shown in Section 3.1, the deviations resulting from the mechanism reduction were considerably smaller. Since ethylene is produced predominantly by the dehydrogenation of its (underpredicted) precursor $\mathrm{C}_{2} \mathrm{H}_{6}$, it is probable that the smaller disagreement of $\mathrm{C}_{2} \mathrm{H}_{4}$ is rather a coincidence. It therefore appears that $\mathrm{C}_{2} \mathrm{H}_{6}$ formation might be underestimated, while at the same time the dehydrogenation channel of $\mathrm{C}_{2} \mathrm{H}_{6}$ to $\mathrm{C}_{2} \mathrm{H}_{4}$ is overestimated. The estimated mole fractions for $\mathrm{C}_{2} \mathrm{H}_{2}, \mathrm{C}_{3} \mathrm{H}_{8}$ and $\mathrm{C}_{3} \mathrm{H}_{6}$ are in agreement the simulation trends. Since the LIF measurements are non-quantitative no judgment on the $\mathrm{CH}_{2} \mathrm{O}$ concentrations can be made.

\subsection{Kinetic Discussion}

It is of interest to use the mechanism to reveal the underlying kinetic pathways of methane oxidation at the above conditions. The fundamental kinetics of methane oxidation are well understood, even if as seen above the rate coefficients are not always suitably accurate for all conditions. The mechanism by which methane is oxidized changes with temperature, and it is commonly divided into a low-temperature and a hightemperature pathway. OCM is unusual in that it is highly fuel rich and thus a combination of oxidation and pyrolysis. The current conditions correspond to the upper limit in temperature of the low-temperature oxidation regime.

To generate the flux diagram, a plug-flow reactor was performed in CHEMKIN-PRO, using the experiment's temperature profile to fix the energy equation. A reaction path analysis was performed for three positions along the reactor, each position being representative for a certain temperature regime along the reaction coordinate, i.e. 700,900 and $1100 \mathrm{~K}$. In the following we provide a qualitative description for the three reaction domains; the respective flux diagrams are presented in Figure 11 .

At the inlet, the temperature is low $(700 \mathrm{~K})$, which is solidly in the low-temperature kinetic regime. The initiation reaction is

$$
\mathrm{CH}_{4}+\mathrm{O}_{2} \rightleftharpoons \mathrm{CH}_{3} \cdot+\mathrm{HO}_{2}
$$

At this temperature, we have the following sequence of reactions:

$$
\mathrm{CH}_{3}+\mathrm{O}_{2}+\mathrm{M} \rightleftharpoons \mathrm{CH}_{3} \mathrm{OO}^{\circ}+\mathrm{M}
$$



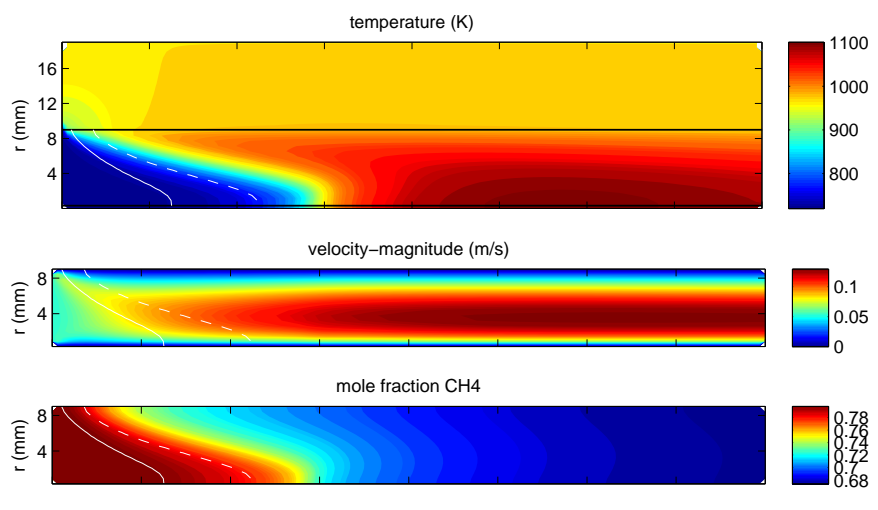

mole fraction $\mathrm{O} 2$
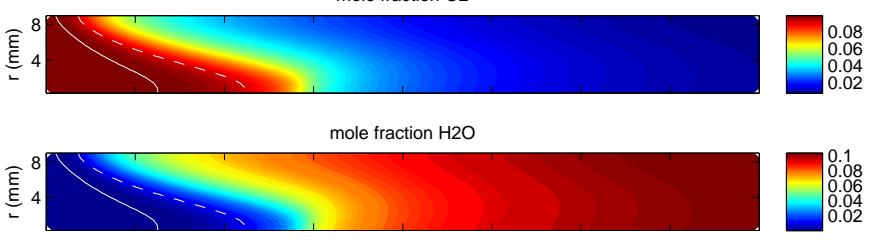

mole fraction $\mathrm{H} 2$

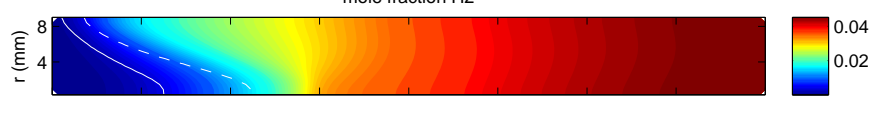

mole fraction $\mathrm{CO}$
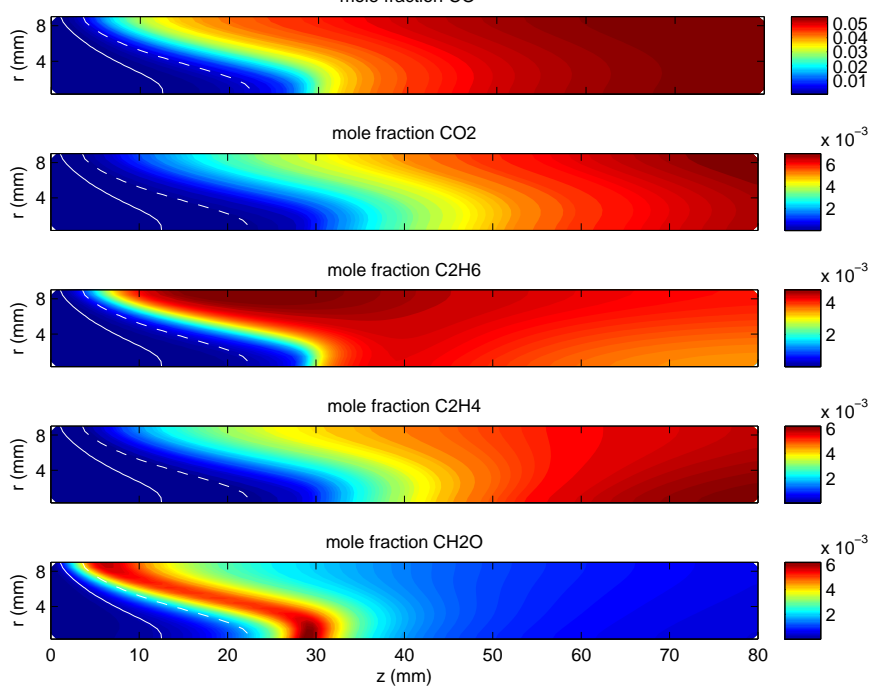

Figure 9: Numerical simulation contours of temperature, velocity and major species' mole fractions in cylindrical coordinates. The symmetry axis is at the bottom, the reactor entry is on the left and the flow direction is from left to right. As a guide for the eye the 0.099 and 0.09 isolines of the $\mathrm{O}_{2}$ molar fraction (i.e. 1 and $10 \%$ conversion) is indicated as white lines.

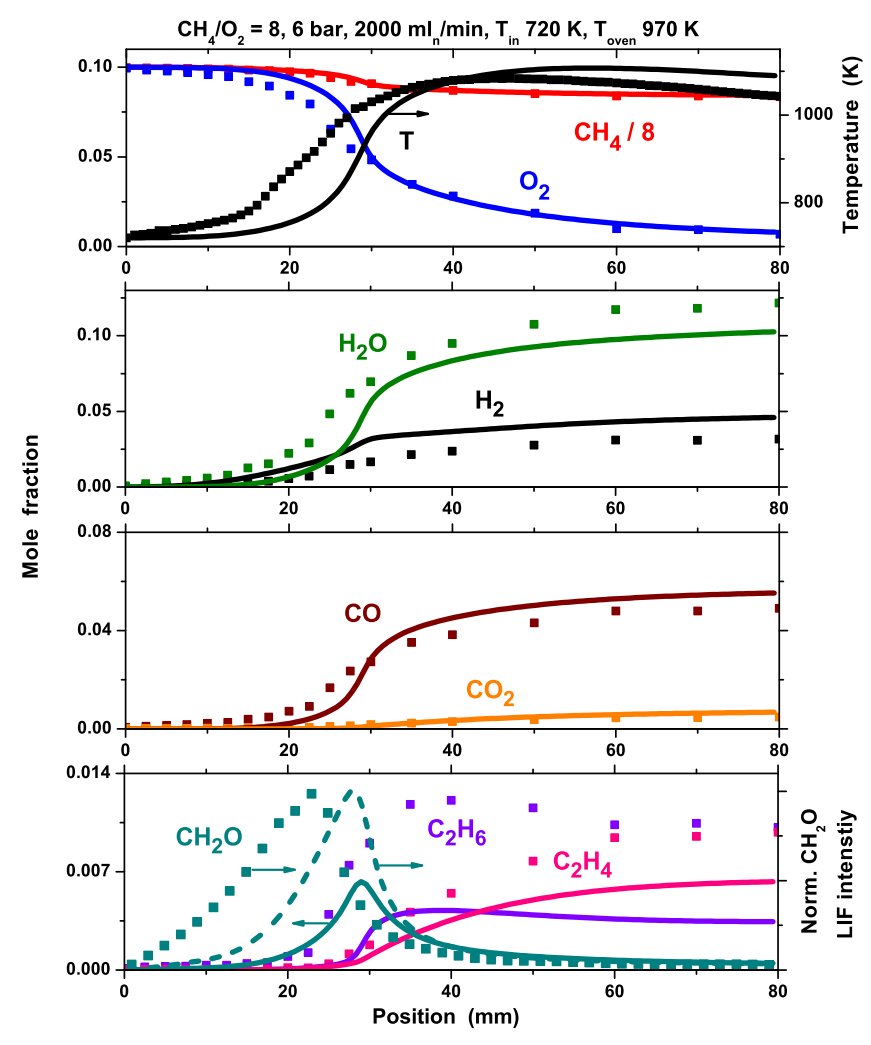

Figure 10: Experimental (marks) and simulated (lines) temperature and speciation profiles. Mole fractions for all species are depicted with respect to the left axis. In the top graph also the temperature is given with respect to the right axis, while the bottom plot includes the experimental (marks) and simulated (dashed line) normalized $\mathrm{CH}_{2} \mathrm{O}$ LIF intensities on the right axis. Conditions correspond to a $\mathrm{CH}_{4} / \mathrm{O}_{2}$ feed ratio of 8,6 bar pressure, and a total flow rate of $2000 \mathrm{ml}_{n} / \mathrm{min}$. The simulation results are based on the reduced kinetic mechanism of Dooley [29]. 


$$
\begin{gathered}
\mathrm{CH}_{3} \mathrm{OO}+\mathrm{CH}_{4} \rightleftharpoons \mathrm{CH}_{3} \mathrm{OOH}+\mathrm{CH}_{3} \\
\mathrm{CH}_{3} \mathrm{OO}+\mathrm{HO}_{2} \rightleftharpoons \mathrm{CH}_{3} \mathrm{OOH}+\mathrm{O}_{2} \\
\mathrm{CH}_{3} \mathrm{OOH}+\mathrm{M} \rightleftharpoons \mathrm{CH}_{3} \mathrm{O}+\mathrm{OH} \\
\mathrm{CH}_{3} \mathrm{O}+\mathrm{M} \rightleftharpoons \mathrm{CH}_{2} \mathrm{O}+\mathrm{H}+\mathrm{M}
\end{gathered}
$$

With these six reactions, a radical pool is established consisting of $\mathrm{H}^{\circ}, \mathrm{OH}, \mathrm{CH}_{3}{ }^{\circ}, \mathrm{CH}_{3} \mathrm{O}, \mathrm{HO}_{2}{ }^{\circ}$, and $\mathrm{CH}_{3} \mathrm{OO}$. Once the radical pool is established, most methyl is generated not by $\mathrm{R} 1$ but through $\mathrm{H}$-abstraction from methane via $\mathrm{R} 3$ and R7-R9:

$$
\begin{gathered}
\mathrm{CH}_{4}+\mathrm{OH} \rightleftharpoons \mathrm{CH}_{3}+\mathrm{H}_{2} \mathrm{O} \\
\mathrm{CH}_{4}+\mathrm{H}^{\cdot} \rightleftharpoons \mathrm{CH}_{3}+\mathrm{H}_{2} \\
\mathrm{CH}_{4}+\mathrm{HO}_{2} \rightleftharpoons \mathrm{CH}_{3} \cdot \mathrm{HOOH}
\end{gathered}
$$

The first six reactions convert $\mathrm{CH}_{4}$ into $\mathrm{CH}_{2} \mathrm{O}$, which is converted to $\mathrm{HCO}$, which in turn either decomposes or reacts with oxygen to yield $\mathrm{CO}$ :

$$
\begin{aligned}
& \mathrm{CH}_{2} \mathrm{O}+\mathrm{CH}_{3} \mathrm{OO}^{\circ} \rightleftharpoons \mathrm{HCO}^{\circ}+\mathrm{CH}_{3} \mathrm{OOH} \\
& \mathrm{CH}_{2} \mathrm{O}+\mathrm{CH}_{3} \rightleftharpoons \mathrm{HCO}+\mathrm{CH}_{4} \\
& \mathrm{CH}_{2} \mathrm{O}+\mathrm{HO}_{2} \rightleftharpoons \mathrm{HCO}+\mathrm{HOOH} \\
& \mathrm{CH}_{2} \mathrm{O}+\mathrm{OH}^{\circ} \rightleftharpoons \mathrm{HCO}^{\circ}+\mathrm{H}_{2} \mathrm{O} \\
& \mathrm{CH}_{2} \mathrm{O}+\mathrm{H}^{\cdot} \rightleftharpoons \mathrm{HCO}^{\circ}+\mathrm{H}_{2} \\
& \mathrm{HCO}^{\circ}+\mathrm{M} \rightleftharpoons \mathrm{CO}+\mathrm{H}^{\circ}+\mathrm{M} \\
& \mathrm{HCO}^{\circ}+\mathrm{O}_{2} \rightleftharpoons \mathrm{CO}+\mathrm{HO}_{2}
\end{aligned}
$$

At this point the only stable carbon-containing products are $\mathrm{CH}_{2} \mathrm{O}$ and $\mathrm{CO}$. In Figure 11a, we see that most of the $\mathrm{CH}_{4}$ is broken down by $\mathrm{OH}$, followed by $\mathrm{CH}_{3} \mathrm{OO}, \mathrm{H}^{-}$, and $\mathrm{HO}_{2}$. Virtually all of the $\mathrm{CH}_{3}$ reacts with oxygen to form $\mathrm{CH}_{3} \mathrm{OO}$. The $\mathrm{CH}_{3} \mathrm{OO}$ reacts with $\mathrm{CH}_{4}$ and with $\mathrm{HO}_{2}$. $\mathrm{CH}_{3} \mathrm{OOH}$ decomposes via R5. Eventually $\mathrm{CH}_{2} \mathrm{O}$ builds up, which reacts with $\mathrm{CH}_{3} \mathrm{OO}$ and $\mathrm{HO}_{2}$ to form $\mathrm{HCO}^{\circ}$. $\mathrm{HCO}$ is mostly consumed by $\mathrm{O}_{2}$, yielding $\mathrm{CO}$.

Another important reaction is:

$$
\mathrm{H}+\mathrm{O}_{2}+\mathrm{M} \rightleftharpoons \mathrm{HO}_{2}+\mathrm{M}
$$

Even though R16 and R17 are chain propagating, they convert a reactive radical $\left(\mathrm{H}^{\cdot}\right.$ or $\left.\mathrm{HCO}^{\circ}\right)$ into a more stable radical $\left(\mathrm{HO}_{2}{ }^{\circ}\right)$, and thus temporarily slow down oxidation. Additionally, there is also the chain terminating reaction:

$$
\mathrm{HO}_{2}+\mathrm{HO}_{2} \rightleftharpoons \mathrm{HOOH}+\mathrm{O}_{2}
$$

Reaction R9, R12, and R18 form hydrogen-peroxide, $\mathrm{HOOH}$. Once there is sufficient $\mathrm{HOOH}$, a new chain-branching reaction becomes competitive:

$$
\mathrm{HOOH}+\mathrm{M} \rightleftharpoons \mathrm{OH}+\mathrm{OH}^{\cdot}+\mathrm{M}
$$

$\mathrm{R} 19$ is quite slow at these temperatures, $\mathrm{so}^{\mathrm{HO}}{ }_{2}$ formation generally acts like a radical sink. The decomposition of methylhydroperoxide $\mathrm{R} 5$ is the main chain branching reaction. At higher temperatures, however, R19 becomes much faster and ultimately becomes the main chain branching reaction in the reaction zone.

R1-R19 is an abbreviated description of the classical lowtemperature mechanism for $\mathrm{CH}_{4}$ oxidation. Numerous cross reactions have been omitted for clarity (for example: some $\mathrm{CH}_{3} \mathrm{O}$. will abstract $\mathrm{H}$-atoms to form methanol, which has its own submechanism, but it is irrelevant for the present conditions).

The reaction zone is characterized by rapid $\mathrm{O}_{2}$ conversion, product build-up, and a sharp profile for the intermediate $\mathrm{CH}_{2} \mathrm{O}$ at a temperature around $900 \mathrm{~K}$. This temperature is close to the upper limit at which $\mathrm{CH}_{3} \mathrm{OO}$ is stable, with the equilibrium constant beginning to shift back in favor of the bimolecular reactants (cf. reaction R2). Some of the $\mathrm{CH}_{3}$ still reacts with $\mathrm{O}_{2}$ to form $\mathrm{CH}_{3} \mathrm{OO}$, but it is now a minor channel. The most important sink for $\mathrm{CH}_{3}$ is the reaction with $\mathrm{HO}_{2}{ }^{\circ}$ and to a smaller extent with $\mathrm{O}_{2}$ :

$$
\begin{aligned}
\mathrm{CH}_{3}{ }^{\circ}+\mathrm{HO}_{2} \rightleftharpoons \mathrm{CH}_{3} \mathrm{O}+\mathrm{OH}^{\circ} \\
\mathrm{CH}_{3}+\mathrm{O}_{2} \rightleftharpoons \mathrm{CH}_{2} \mathrm{O}+\mathrm{OH}^{\circ}
\end{aligned}
$$

After R20, the next most important reaction is R22, the main coupling reaction:

$$
\mathrm{CH}_{3}+\mathrm{CH}_{3}+\mathrm{M} \rightleftharpoons \mathrm{C}_{2} \mathrm{H}_{6}+\mathrm{M}
$$

Roughly $85 \%$ of the $\mathrm{CH}_{3}$ goes through R20, and only $10 \%$ through R22, thereby opening up the $\mathrm{C}_{2}$ channel. The $\mathrm{CH}_{3} \mathrm{OO}$ channel is minor at this point, and the main chain branching sequence at $700 \mathrm{~K}$ (R2-R5) becomes almost irrelevant at $900 \mathrm{~K}$. Instead, the formation and decomposition of $\mathrm{HOOH}-$ reactions R9, R12, R18, and R19 - is now the main chain branching sequence. The slow build-up of $\mathrm{HOOH}$ reaches a tipping point at the start of the reaction front, which leads to spontaneous growth in $\mathrm{OH}^{-}$production, which accelerates both the formation and decomposition of $\mathrm{CH}_{2} \mathrm{O}$. The rapid increase in $\mathrm{CH}_{2} \mathrm{O}$

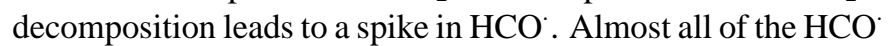
reacts with $\mathrm{O}_{2}$, which is the main reaction for $\mathrm{O}_{2}$ consumption.

As $\mathrm{C}_{2} \mathrm{H}_{6}$ builds up, it reacts with $\mathrm{OH}, \mathrm{H}^{*}, \mathrm{CH}_{3}$, and to a lesser extent $\mathrm{HO}_{2}$ to form ethyl. Virtually all of the $\mathrm{C}_{2} \mathrm{H}_{5}$ reacts with $\mathrm{O}_{2}$ to form $\mathrm{C}_{2} \mathrm{H}_{4}+\mathrm{HO}_{2}$.

Behind the reaction front the temperature has reached almost $1100 \mathrm{~K}$. The coupling reaction $\mathrm{R} 22$ becomes the most important sink for $\mathrm{CH}_{3}$, followed by the reactions with $\mathrm{HO}_{2}{ }^{\circ}$, and $\mathrm{CH}_{2} \mathrm{O}$. At this temperature $\mathrm{CH}_{3} \mathrm{OO}$ is not stable; the equilibrium constant has shifted back to the bimolecular reactants, and the reaction sequence R2-R5 is inconsequential. Additionally, the increase in temperature now allows for the oxidation of $\mathrm{CO}$. The reaction of $\mathrm{CO}$ with $\mathrm{HO}_{2}$ and $\mathrm{OH}$ releases considerably heat, creating a positive thermal feedback loop.

$$
\begin{aligned}
\mathrm{CO}+\mathrm{HO}_{2} & \rightleftharpoons \mathrm{CO}_{2}+\mathrm{OH} \\
\mathrm{CO}+\mathrm{OH} & \rightleftharpoons \mathrm{CO}_{2}+\mathrm{H}^{\circ}
\end{aligned}
$$

In the $\mathrm{C}_{2}$ pathway the only differences are: (i) the build-up of $\mathrm{C}_{2} \mathrm{H}_{4}$ causes the thermal decomposition of $\mathrm{C}_{2} \mathrm{H}_{5}$ to run in reverse (i.e. $\mathrm{H}^{-}+\mathrm{C}_{2} \mathrm{H}_{4} \rightarrow \mathrm{C}_{2} \mathrm{H}_{5}{ }^{\circ}$ ), (ii) the onset of high-molecular weight growth (not shown). 
The formation and decomposition of $\mathrm{HOOH}$ is still the main chain branching sequence. Even at $1100 \mathrm{~K}$, the temperature is still too low for

$$
\mathrm{H}^{\cdot}+\mathrm{O}_{2} \rightleftharpoons \mathrm{OH}^{\cdot}+\mathrm{O}
$$

The temperature is high enough that $\mathrm{CH}_{3} \mathrm{OO}$ is minor, but it is low enough that $\mathrm{R} 17$ dominates $\mathrm{R} 25$ (i.e. $\mathrm{H}+\mathrm{O}_{2}$ gives $\mathrm{HO}_{2}$ instead of $\left.\mathrm{OH}^{-}+\mathrm{O}\right)$, so oxidation is still slow and incomplete.

\section{Conclusion}

We presented kinetic profile measurements and numerical simulations for fuel-rich methane partial oxidation stoichiometries encountered in methane oxidative coupling, the results of which are representative of a set of experiments performed under different conditions (by varying composition $\mathrm{CH}_{4} / \mathrm{O}_{2} 4$ 16 and pressure $1-8$ bar). The experiment was conducted at a pressure of 6 bar with a $\mathrm{CH}_{4} / \mathrm{O}_{2}$ ratio of 8 and temperatures around $900 \mathrm{~K}$ in a versatile flow reactor with spatial sampling capabilities. Use of a novel technique for laser-induced fluorescence (LIF) detection of $\mathrm{CH}_{2} \mathrm{O}$ using an optical fiber probe was demonstrated. Full Navier-Stokes kinetic numerical simulation were performed using a reduced version of the mechanism by Dooley et al. [29], and the results were compared to the experimental data.

The results show that predictive kinetic modeling of industrial processes is still challenging. Comprehensive and numerically expensive simulations have to assure the accurate description of both physical and chemical processes in the reactor. Not only accurate kinetic mechanisms but also heat and mass transport properties play an important role in the evaluation of the profiles. The results suggest that the mechanism gives qualitatively and quantitatively correct predictions for the main species. However, in particular the evolution of the $\mathrm{C}_{2}$ species appears to be captured less accurately. As a systematic difference between experiment and simulation it was observed that the mole fraction profiles of $\mathrm{C}_{2} \mathrm{H}_{6}$ and $\mathrm{C}_{2} \mathrm{H}_{4}$ are predicted too low.

The findings give interesting insight into the kinetics of fuelrich methane oxidation at the upper limit of the low-temperature kinetic regime in particular with respect to $\mathrm{C}_{2}$ formation. It is noteworthy that formation of $\mathrm{C}_{2}$ species through coupling of methyl radicals is possible in the pure gas-phase. However, the selectivity observed in the gas-phase is poor. Under industrial catalytic high-pressure conditions gas-phase reactions are likely to occur in parallel to heterogeneous reactions which may lead to homogeneous-heterogeneous coupling. The inclusion of gasphase chemistry in modeling is thus a prerequisite for design of an efficient process.

\section{Acknowledgments}

The authors kindly appreciate the financial support granted by the "Cluster of Excellence Unifying Concepts in Catalysis" (UniCat), Berlin. CFG gratefully acknowledges financial support from the Alexander von Humboldt Foundation.

\section{References}

[1] Y. Amenomiya, V. I. Birss, M. Goledzinowski, J. Galuszka, A. R. Sanger, Catalysis Reviews: Science and Engineering 32 (1990) 163-227.

[2] F. G. Billaud, C. P. Gueret, F. Baronnet, Industrial \& Engineering Chemistry Research 31 (1992) 2748-2753.

[3] D. J. Driscoll, W. Martir, J. X. Wang, J. H. Lunsford, J. Am. Chem. Soc. 107 (1985) 58-63.

[4] J. H. Lunsford, Angewandte Chemie International Edition in English 34 (1995) 970-980.

[5] G. J. Hutchings, M. S. Scurrell, J. R. Woodhouse, Journal of the Chemical Society, Chemical Communications (1988) 253.

[6] G. S. Lane, E. E. Wolf, Journal of Catalysis 113 (1988) 144-163.

[7] K. Asami, K. Omata, K. Fujimoto, H.-o. Tominaga, Journal of the Chemical Society, Chemical Communications (1987) 1287.

[8] J. C. Mackie, Catalysis Reviews 33 (1991) 169-240.

[9] R. Horn, O. Korup, M. Geske, U. Zavyalova, I. Oprea, R. Schlogl, Review of Scientific Instruments 81 (2010) 064102.

[10] H. Schwarz, R. Schlögl, R. Horn, Applied Physics B 109 (2012) 19-26.

[11] C. Miesse, R. Masel, M. Short, M. Shannon, Combustion Theory and Modelling 9 (2005) 77-92.

[12] C. A. Mims, R. Mauti, A. M. Dean, K. D. Rose, J. Phys. Chem. 98 (1994) $13357-13372$.

[13] G.-L. Lan, P. K. Banerjee, S. S. Mitra, Journal of Raman Spectroscopy 11 (1981) 416-423.

[14] H. Imai, H. Hirashima, Journal of Non-Crystalline Solids 179 (1994) $202-213$.

[15] P. Karlitschek, G. Hillrichs, K. F. Klein, Optics Communications 116 (1995) 219-230.

[16] P. Karlitschek, G. Hillrichs, K. F. Klein, Optics Communications 155 (1998) 386-397.

[17] J. E. Harrington, K. C. Smyth, Chemical Physics Letters 202 (1993) 196202.

[18] C. Brackmann, J. Nygren, X. Bai, Z. Li, H. Bladh, B. Axelsson, I. Denbratt, L. Koopmans, P.-E. Bengtsson, M. Aldén, Spectrochimica Acta Part A: Molecular and Biomolecular Spectroscopy 59 (2003) 3347-3356.

[19] G. Herzberg, Molecular Spectra and Molecular Structure: II. Infrared and Raman Spectra of Polyatomic Molecules, Molecular Spectra and Molecular Structure, D. Van Nostrand Company, Inc., 1964.

[20] D. J. Clouthier, D. A. Ramsay, Annu. Rev. Phys. Chem. 34 (1983) 31-58.

[21] B. Maessen, M. Wolfsberg, The Journal of Chemical Physics 80 (1984) 4651.

[22] G. H. Dieke, G. B. Kistiakowsky, Physical Review 45 (1934) 4-28.

[23] C. Brackmann, J. Bood, M. Aldén, G. Pengloan, Ö. Andersson, Combustion Science and Technology 178 (2006) 1165-1184.

[24] G. Herzberg, Molecular Spectra and Molecular Structure: III. Electronic Spectra of Polyatomic Molecules, Molecular Spectra and Molecular Structure, D. Van Nostrand Company, Inc., 1966.

[25] D. I. Shin, G. Peiter, T. Dreier, H.-R. Volpp, J. Wolfrum, Proceedings of the Combustion Institute 28 (2000) 319-325.

[26] D. Shin, T. Dreier, J. Wolfrum, Applied Physics B 72 (2001) 257-261.

[27] J. Tobai, T. Dreier, Applied Physics B: Lasers and Optics 74 (2002) 101104.

[28] A. Ehn, O. Johansson, J. Bood, A. Arvidsson, B. Li, M. Aldén, Proceedings of the Combustion Institute 33 (2011) 807-813.

[29] S. Dooley, M. P. Burke, M. Chaos, Y. Stein, F. L. Dryer, V. P. Zhukov, O. Finch, J. M. Simmie, H. J. Curran, International Journal of Chemical Kinetics 42 (2010) 527-549.

[30] J. Li, Z. Zhao, A. Kazakov, F. L. Dryer, International Journal of Chemical Kinetics 36 (2004) 566-575.

[31] D. Healy, H. Curran, J. Simmie, D. Kalitan, C. Zinner, A. Barrett, E. Petersen, G. Bourque, Combustion and Flame 155 (2008) 441-448.

[32] V. K. Bityukov, V. A. Petrov, High Temperature 38 (2000) 293-299.

[33] H. Schlichting, Boundary-layer theory, McGraw-Hill series in mechanical engineering, McGraw-Hill, New York, 7 edition, 1979.

[34] R. Kee, M. Coltrin, P. Glarborg, Chemically Reacting Flow: Theory and Practice, John Wiley \& Sons, 2005.

[35] L. L. Raja, R. J. Kee, O. Deutschmann, J. Warnatz, L. D. Schmidt, Catalysis Today 59 (2000) 47-60.

[36] T. Metz, X. Bai, F. Ossler, M. Aldén, Spectrochimica Acta Part A: Molecular and Biomolecular Spectroscopy 60 (2004) 1043-1053. 

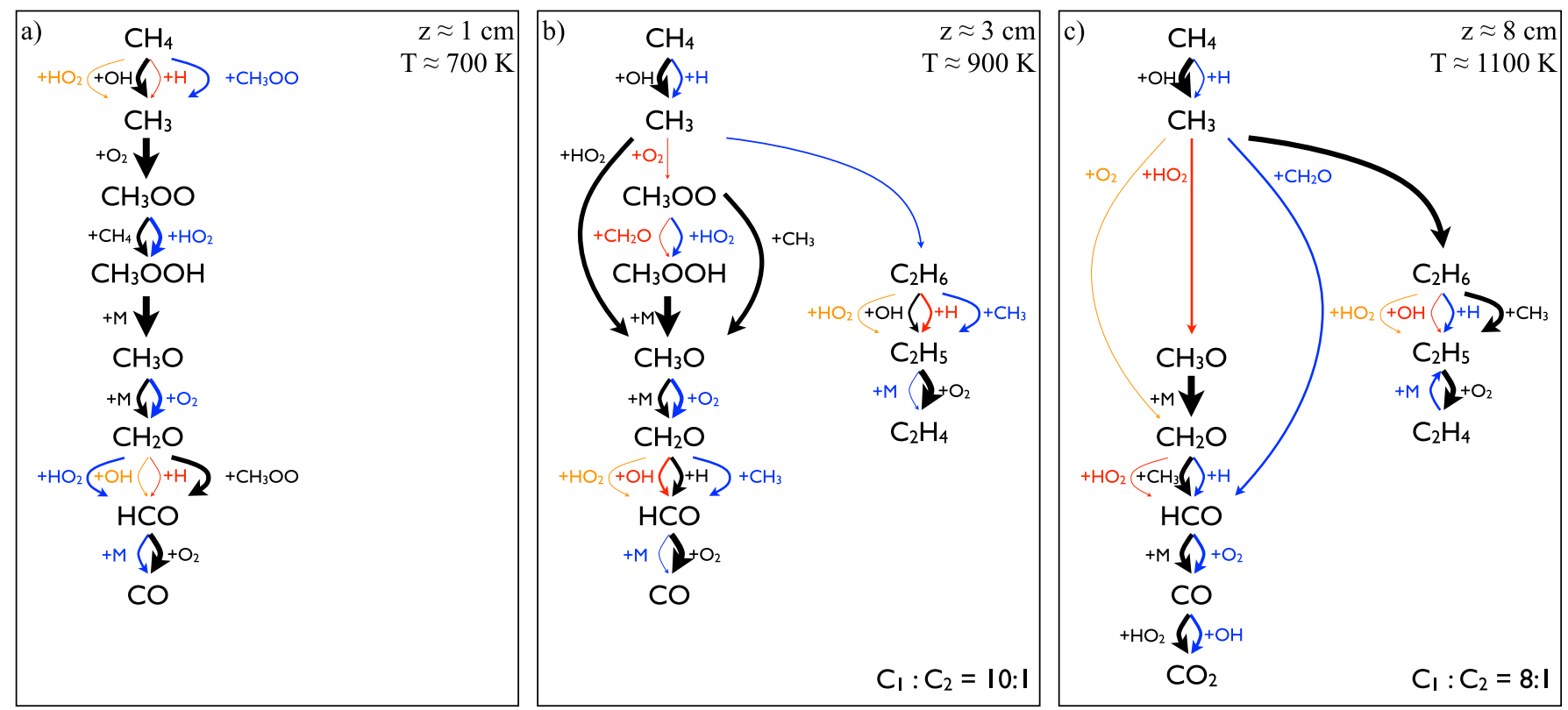

Figure 11: Flux diagrams for three different positions along the reaction coordinate, corresponding to temperatures 700 , 900 and $1100 \mathrm{~K}$. With respect to the experiment, the temperature regimes correspond to the reactor entry, the reaction zone (defined by the steepest $\mathrm{O}_{2}$ gradient) and the exit of the reactor, respectively. The line color and thickness indicate the relative importance of each pathway, with the black lines being the most dominant, followed by blue, red, then orange.

[37] C. Brackmann, Z. Li, M. Rupinski, N. Docquier, G. Pengloan, M. Aldén, Applied Spectroscopy 59 (2005) 763-768.

[38] B. Connelly, B. Bennett, M. Smooke, M. Long, Proceedings of the Combustion Institute 32 (2009) 879-886.

[39] Z. Zhao, M. Chaos, A. Kazakov, F. L. Dryer, International Journal of Chemical Kinetics 40 (2008) 1-18.

[40] S. Bhattacharjee, W. L. Grosshandler, Combustion and Flame 77 (1989) 347-357.

[41] C. L. Tien, in: J. T. F. Irvine, J. P. Hartnett (Eds.), Advances in Heat Transfer, volume 5, Academic Press, New York, 1968, pp. 253-324. 